Dipartimento di Scienze Statistiche

Sezione di Statistica Economica ed Econometria

M. Grazia Pittau, Shlomo Yitzhaki, Roberto Zelli

The make-up of a regression coefficient: gender gaps in the European labour market

DSS Empirical Economics and Econometrics

Working Papers Series

DSS-E3 WP 2013/4 
Dipartimento di Scienze Statistiche Sezione di Statistica Economica ed Econometria "Sapienza" Università di Roma P.le A. Moro 5-00185 Roma - Italia http://www.dss.uniromal.it 


\title{
The "Make-up" of a Regression Coefficient: Gender Gaps in the European Labor Market
}

\author{
M. Grazia Pittau ${ }^{1}$, Shlomo Yitzhaki ${ }^{2}$, and Roberto Zelli ${ }^{1}$ \\ ${ }^{1}$ Department of Statistical Science, Sapienza University of Rome \\ ${ }^{2}$ The Hebrew University of Jerusalem and Central Bureau of Statistics
}

\begin{abstract}
We provide a comprehensive picture of the relationship between labor market outcomes and age by gender in all the 28 European countries covered by the European Statistics on Income and Living Conditions (EU-SILC). The analysis is based on a somewhat unconventional approach that refers to concentration curves in the context of Gini regression framework. It allows to identify ranges in the explanatory variables where local slopes change sign and/or size, i.e. the components that "make up" a regression coefficient. The European countries are clustered into five groups according to their employment, hours of work and earnings age-profiles by gender, as identified by the concentration curves. The most relevant differences in age profiles concern working-hours-patterns: some countries are characterized by an almost specular behavior in men and women; other countries instead show similar patterns. Generally, earnings increase with age for both men and women. However, local regression coefficients are not monotonic over the entire age range and can even be locally negative in some countries.
\end{abstract}

Keywords: Gini regression, Concentration curves, labor market, age profile, gender gap. JEL Classification: C30, J16, J21. 


\section{Introduction}

Although in Europe there is a documented trend towards a narrowing gender gap in the labor market, there are still significant gender inequalities in terms of participation, working time and earnings (OECD, 2002; European Commission, 2006). These gender inequalities could depend on differences in education, skill experiences, underestimation and discrimination. A large body of literature has tried to explain gender pay gap as differences related to human capital and other "unexplained" characteristics potentially associated with discrimination (Blau and Kahn, 2000). Age is a key factor in the labor market, not only as a proxy for experience but also in the shaping of longterm dynamics in the structure of paid labor force and distribution of working hours. Age structure influences participation in the labor market according to a three-part division: younger individuals are less likely to participate because they are involved in formal schooling, senior individuals are likely to leave the labor-force around their sixties for retirement, the intermediate age group represents the "working age" population. Of course participation of individuals in the labor market is also affected by a variety of other circumstances such as cultural traditions, productive structure and labor regulation, which can significantly influence average working hours. As women and men age, their willingness to work, their amount of time set aside for work and ultimately their earnings differentiate: age carries important implications for gender disparities in the labor market (Lee at al., 2007). Notwithstanding a tremendous literature on gender gap in European labor markets, there is still a scarcity of cross-country studies of gender gap profiles in Europe. Based on EU-SILC data set, this paper provides a comprehensive picture of the relationship between labor market outcomes and age by gender in Europe. The European Statistics on Income and Living Conditions (EU-SILC) is a collection of annual national surveys of socio-economic conditions of individuals and households in the EU countries. All national surveys in EU-SILC have standard questionnaires and procedures for data processing and yield ex-ante harmonized microdata that allow homogeneous inter-country comparisons using a uniform protocol.

This study embodies a somewhat unconventional approach to identify age profiles of labor market outcomes. This approach, originally illustrated in Yitzhaki and Schechtman (2012) is based on the use of concentration curves in the context of a Gini regression framework. Unlike simple OLS regression, this methodology allows to investigate non-monotonicity between two variables. It has also advantages over conventional non-parametric regression methods since it goes beyond the visual impression of non-parametric curves making possible the identification of ranges in the explanatory variables where local slopes change sign and/or size. In other words, we are able to investigate the components that "make up" a regression coefficient.

The paper is articulated as follows: after the present introduction, Section 2 describes 
the data and provides a comprehensive cross-country summary of the labor market variables used in the profile analysis. Section 3 presents a brief review of our methodology based on concentration curves and Gini regression coefficients. Section 4 reports the main empirical results on the relationship between labor market outcomes (namely labor participation, hours of work and earnings) and age by gender in Europe. We cluster European countries according to their age profiles and for each cluster a representative country is more deeply investigated. Section 5 offers conclusions and suggestions for further research.

\section{Data, definitions and early evidence}

The lack of comparable data has often prevented comprehensive analysis of gender disparities across a large set of countries. Furthermore, problems in sample coverage, ${ }^{1}$ quality of data and the fact that labor market outcomes are often based on different definitions, hampered comparability even within Europe. The European Union Survey on Income and Living Conditions (EU-SILC) overcomes these concerns since the national surveys are based on a standard questionnaire and provide ex-ante harmonized micro-data on European countries. We used data from the latest release of the 2008 wave, which collects information on household activities related to the year $2007^{2}$.

Since our analysis focuses on the structure of employment, hours of work and earnings by age and gender, we selected, for each respondent, age, personal cross-sectional sampling weight, activity status, average weekly hours of work in main and secondary activities, employee income and self-employed income. For most of the countries we were able to identify age in terms of years and quarters. We selected individuals aged between 18 and 65, which corresponds to the typical end of high school and the most frequent year of retirement in Europe.

In the following we give a description of the variables (for more details see the reference manual: Eurostat, 2009). Each household respondent (of any age) is labelled by his/her activity status coded as PX050. Activity status is calculated on the basis of questions concerning number of months spent at full-time work, at part-time work, in unemployment, in retirement, studying, and in inactivity. The respondent is identified as employed (full-time and part-time), unemployed, retired, or in other inactivities if the respondent has spent more than six months in that status. If the respondent has not spent at least six months in none of those status, the variable is coded as missing/undefined.

Disparities between women and men in the labor market are evident in two primary measures: labor force participation rates (the gender participation gap) and average

\footnotetext{
${ }^{1}$ Using only particular subsets of the population - e.g. workers in private sector, employee wage earners, full time workers, or taxpayers - can result in biased estimates.

${ }^{2}$ Cross-sectional UDB SILC 2008 Rev.4, March 2012.
} 
earnings (the gender wage gap). Participation rate can be defined as the percentage of employed and unemployed over the total population aged 18-65. To better relate labor participation and wages, we follow the literature in estimating employment rates by gender, as the ratio between employed and total population aged 18-65.

Table 1 lists the countries covered by EU-SILC, the number of workers in the sample and the estimated employment rate by gender in 2008. The employment gap is measured as the difference between men's and women's employment rates as a percentage of men's employment rate. It ranges from $6.3 \%$ in Iceland to $34.8 \%$ in Italy. In line with the findings of previous studies (e.g. OECD, 2002), Mediterranean countries as well as most Eastern European countries are characterized by wide gaps. For Italy, Hungary and Poland this alarming scenario is further amplified by relatively low male employment rates. Nordic countries, instead, display the lowest employment gaps among the EU economies, accompanied by high levels of employment rates for both men and women.

Earnings are defined as the total gross annual remuneration, in cash or in kind, payable by an employer to an employee for work done by the latter during the income reference period. ${ }^{3}$ Employee income is composed of gross employee cash or near cash income, gross non-cash employee income, and employer's social insurance contribution. Selfemployment income includes gross cash benefits or losses from self-employment including royalties, and value of goods produced for personal consumption. An individual can earn his/her labor income from multiple activities. Therefore an individual can earn simultaneously wages and self-employment income. ${ }^{4}$

Most of European countries are characterized by high incidence of part-time employment and flexibility in working hours among women, which should be accounted in order to fully evaluate gender gaps in the labor market. Hours of work are the number of hours a person normally works in a week in his/her job. In the EU-SILC survey, this covers all hours including extra hours, whether paid or unpaid, which the person normally works, but does not cover travel time to work and main meal breaks. If multiple jobs are held, respondents are asked to indicate the number of working hours in the main job and in the subsidiary jobs. The main job is the one with the greatest number

\footnotetext{
${ }^{3}$ The use of gross income is due to data availability. EU-SILC follows the Canberra group recommendation on income that suggests to collect gross incomes at component level leaving to the single national statistical offices the decision to implement the collection also of net incomes. In 2008, the year of our analysis, several countries, like Germany, Denmark, Finland, Netherlands, Norway and UK, do not display data on net incomes. Gender differences may be slightly over-estimated where measurement is based on gross incomes because of the inclusion of taxes and social security contributions (OECD, 2012). For example, second earners, who are often women, will be subject to different tax thresholds than their partners in many countries.

${ }^{4}$ For some countries, this phenomenon is particularly prominent. In Italy for example the estimated percentage of people who simultaneously receive employee and self-employment earnings represents $22.5 \%$ of total employment.
} 
Table 1: Employment rates by gender and relative gap in the European countries covered by EU-SILC, 2008.

Country EU status* Sample size Employment rate

\begin{tabular}{|c|c|c|c|c|c|c|}
\hline & & & & Women & Men & Gap (\%) \\
\hline At & Austria & $\mathrm{E}$ & 8298 & 59.8 & 77.7 & 23.1 \\
\hline $\mathrm{Be}$ & Belgium & $\mathrm{E}$ & 9352 & 59.1 & 70.9 & 16.7 \\
\hline $\mathrm{Bg}$ & Bulgaria & $\mathrm{N}$ & 7392 & 59.3 & 72.8 & 18.5 \\
\hline $\mathrm{Cy}$ & Cyprus & $\mathrm{N}$ & 6214 & 61.0 & 78.8 & 22.6 \\
\hline $\mathrm{Cz}$ & Czech Republic & $\mathrm{N}$ & 16900 & 57.5 & 76.8 & 25.1 \\
\hline $\mathrm{Dk}$ & Denmark & $\mathrm{E}$ & 8928 & 68.0 & 77.3 & 12.0 \\
\hline $\mathrm{Ee}$ & Estonia & $\mathrm{N}$ & 7911 & 70.5 & 78.2 & 9.9 \\
\hline $\mathrm{Fi}$ & Finland & $\mathrm{E}$ & 16594 & 68.6 & 75.2 & 8.8 \\
\hline $\mathrm{Fr}$ & France & $\mathrm{E}$ & 15138 & 63.2 & 71.8 & 12.0 \\
\hline De & Germany & $\mathrm{E}$ & 17677 & 61.1 & 73.3 & 16.6 \\
\hline $\mathrm{Gr}$ & Greece & $\mathrm{E}$ & 9992 & 51.0 & 76.5 & 33.3 \\
\hline $\mathrm{Hu}$ & Hungary & $\mathrm{N}$ & 14077 & 52.0 & 65.9 & 21.1 \\
\hline Is & Iceland & $\times$ & 5380 & 84.1 & 89.8 & 6.3 \\
\hline Ie & Ireland & $\mathrm{E}$ & 6978 & 58.1 & 70.8 & 18.0 \\
\hline It & Italy & $\mathrm{E}$ & 32420 & 47.6 & 73.0 & 34.8 \\
\hline $\mathrm{Lv}$ & Latvia & $\mathrm{N}$ & 7671 & 67.4 & 77.4 & 12.9 \\
\hline Lt & Lithuania & $\mathrm{N}$ & 7288 & 66.8 & 74.1 & 9.8 \\
\hline $\mathrm{Lu}$ & Luxembourg & $\mathrm{E}$ & 6486 & 56.9 & 77.9 & 26.9 \\
\hline $\mathrm{Nl}$ & The Netherlands & $\mathrm{E}$ & 16090 & 63.2 & 76.1 & 16.9 \\
\hline No & Norway & $x$ & 8478 & 72.3 & 82.8 & 12.6 \\
\hline $\mathrm{Pl}$ & Poland & $\mathrm{N}$ & 24094 & 54.1 & 69.9 & 22.6 \\
\hline $\mathrm{Pt}$ & Portugal & $\mathrm{E}$ & 7141 & 63.2 & 75.8 & 16.7 \\
\hline Ro & Romania & $\mathrm{N}$ & 12033 & 52.5 & 72.3 & 27.4 \\
\hline $\mathrm{Sk}$ & Slovakia & $\mathrm{N}$ & 11149 & 61.5 & 75.3 & 18.3 \\
\hline $\mathrm{Si}$ & Slovenia & $\mathrm{N}$ & 20051 & 58.1 & 68.4 & 15.1 \\
\hline Es & Spain & $\mathrm{E}$ & 22383 & 57.4 & 79.1 & 27.4 \\
\hline $\mathrm{Se}$ & Sweden & $\mathrm{E}$ & 11187 & 75.6 & 81.7 & 7.4 \\
\hline UK & United Kingdom & $\mathrm{E}$ & 10971 & 69.5 & 80.6 & 13.7 \\
\hline
\end{tabular}

* EU status: E-(established) member since before 2004; N-(new) member since 2004; ×-not a member.

Authors' calculation on weighted data from EU-SILC 2008, rev.4. Cross-sectional weights used. 
of hours usually worked. Some respondents, particularly the self-employed and family workers, may not have usual hours, in the sense that their hours vary considerably from week to week or month to month. When the respondent is unable to provide a figure for usual hours for this reason, the average of the hours actually worked per week over the past four weeks is used as a measure of usual hours (Eurostat, 2009).

Table 2 reports annual earnings and average weekly hours of work by gender in the European countries, along with the corresponding gender percentage gaps. The last column displays the percentage gender gap of hourly earnings. Hourly earnings are measured as the ratio of annual earnings over the estimated number of annual working hours. Total annual earnings provide a better idea of how much individuals "take home" (OECD, 2002), while hourly wage is the price of labor and consequently can be considered the most appropriate measure of the gender pay gap.

For all countries, women's earnings are lower than men's, both in terms of hourly earnings and annual earnings, in line with the literature (e.g. Blau and Kahan, 1996, 2003). Women's hourly rates of pay are, on average, $16.3 \%$ less than men's with large variation across countries. The gap in terms of annual earnings gap is more marked, $28.1 \%$ reflecting also the gap in working hours that is equal to $14.1 \%$. The gender gap in hourly earnings is less than $10 \%$ (which roughly corresponds to the mean minus one standard deviation of the gap distribution) in Belgium, Hungary, Ireland, Italy, Poland and Slovenia, while Estonia, Germany, Lithuania, Luxembourg, Norway and UK report a gap greater than $23 \%$ (roughly the mean plus one standard deviation of the distribution).

For OECD countries, several studies (OECD, 2002; Barth et al., 2002; Olivetti, 2008) have observed a strong negative correlation between wage and employment gaps, that is countries with the lowest wage gaps are accompanied with the highest employment gap. As argued in Olivetti and Petrongolo (2008), such negative correlation reveals a different selection process into employment across countries. Countries with higher rate of female labor participation are those with high gender wage gap since the additional participants are essentially women with low labor market "attachments" (low skills and low work experience). Instead, low wage gaps are found in countries where mainly women with high-wage characteristics enter the labor force. When we extend the analysis to extra OECD countries, we find a different picture, at least in Europe. Figure 1 (top left panel) shows a small negative correlation between wage and employment gaps. However, when we split the working population by age groups, correlation between employment rate and hourly wage gaps varies according to age: it becomes positive for the youngest group aged 18-29 (top right panel); slightly negative for workers aged 30-54 (bottom left panel) and negative for 54-65 year olds (bottom right panel). This evidence suggests no selection effect for young generations entering the labor market, while selection occurs as age increases, becoming substantial in the preretirement period, probably due to early exits from employment of low-skilled female 
Table 2: Annual earnings and average weekly hours of work by gender in the European countries covered by EU-SILC, 2008.

\begin{tabular}{|c|c|c|c|c|c|c|c|c|}
\hline \multicolumn{2}{|c|}{ Country } & \multicolumn{3}{|c|}{ Earnings (Euros*) } & \multicolumn{3}{|c|}{ Hours of work } & \multirow{2}{*}{$\begin{array}{c}\text { Hourly Earn. } \\
\text { Gap }(\%)\end{array}$} \\
\hline & & Men & Women & Gap $(\%)$ & Men & Women & Gap (\%) & \\
\hline At & Austria & 41,619 & 28,770 & 30.9 & 44h30' & $35 \mathrm{~h} 10$ & 20.8 & 12.8 \\
\hline $\mathrm{Be}$ & Belgium & 50,284 & 36,012 & 28.4 & $42 \mathrm{~h} 45$ & $33 \mathrm{~h} 50$ & 20.9 & 9.5 \\
\hline $\mathrm{Bg}$ & Bulgaria & 4,278 & 3,266 & 23.6 & $47 \mathrm{~h} 45$ & $45 \mathrm{~h} 40^{\prime}$ & 4.1 & 20.4 \\
\hline $\mathrm{Cy}$ & Cyprus & 29,555 & 19,917 & 32.6 & $44 \mathrm{~h} 25$ & $37 \mathrm{~h} 55$ & 14.6 & 21.1 \\
\hline $\mathrm{Cz}$ & Czech Republic & 13,688 & 9,828 & 28.2 & $45 \mathrm{~h} 25$ & $41 \mathrm{~h} 05$ & 9.6 & 20.5 \\
\hline $\mathrm{Dk}$ & Denmark & 54,229 & 41,464 & 23.5 & $40 \mathrm{~h} 40^{\prime}$ & $35 \mathrm{~h} 55$ & 11.5 & 13.6 \\
\hline $\mathrm{Ee}$ & Estonia & 13,698 & 9,313 & 32.0 & 41h30' & $39 \mathrm{~h} 50$ ' & 3.8 & 29.3 \\
\hline $\mathrm{Fi}$ & Finland & 43,770 & 33,027 & 24.5 & 41h15' & $36 \mathrm{~h} 50$ & 10.5 & 15.7 \\
\hline $\mathrm{Fr}$ & France & 39,636 & 27,824 & 29.8 & 42h10' & $35 \mathrm{~h} 20^{\prime}$ & 16.2 & 16.2 \\
\hline De & Germany & 37,732 & 21,486 & 43.0 & $44 \mathrm{~h} 05$ & $33 \mathrm{~h} 25$ & 25.5 & 23.5 \\
\hline Gr & Greece & 26,918 & 19,260 & 28.4 & 47h35' & 38h30' & 17.5 & 13.3 \\
\hline $\mathrm{Hu}$ & Hungary & 9,322 & 8,157 & 12.5 & $42 \mathrm{~h} 15$ & 40h10’ & 4.9 & 8.0 \\
\hline Is & Iceland & 63,074 & 41,119 & 34.8 & $48 \mathrm{~h} 40$ & $38 h 50$ & 20.1 & 18.4 \\
\hline $\mathrm{Ie}$ & Ireland & 47,708 & 31,802 & 33.3 & $42 \mathrm{~h} 10 ’$ & 30h30' & 27.5 & 8.1 \\
\hline It & Italy & 37,776 & 28,549 & 24.4 & $42 \mathrm{~h} 45^{\prime}$ & $35 \mathrm{~h} 30^{\prime}$ & 16.9 & 9.1 \\
\hline $\mathrm{Lv}$ & Latvia & 10,989 & 8,625 & 21.5 & 44h15 & $41 \mathrm{~h} 40^{\prime}$ & 5.8 & 16.7 \\
\hline Lt & Lithuania & 7,935 & 5,787 & 27.1 & $41 \mathrm{~h} 35$ & 39h30' & 5.1 & 23.1 \\
\hline $\mathrm{Lu}$ & Luxembourg & 67,469 & 41,421 & 38.6 & $43 \mathrm{~h} 40^{\prime}$ & $34 h 55$ & 19.9 & 23.3 \\
\hline $\mathrm{Nl}$ & The Netherlands & 52,238 & 29,369 & 43.8 & $40 \mathrm{~h} 05$ & $28 \mathrm{~h} 00^{\prime}$ & 30.1 & 19.6 \\
\hline No & Norway & 65,738 & 42,285 & 35.7 & $42 \mathrm{~h} 30^{\prime}$ & $35 \mathrm{~h} 55$ & 15.7 & 23.7 \\
\hline $\mathrm{Pl}$ & Poland & 9,551 & 7,889 & 17.4 & $44 \mathrm{~h} 50$ & 40h00' & 10.8 & 7.4 \\
\hline $\mathrm{Pt}$ & Portugal & 19,335 & 14,940 & 22.7 & $42 \mathrm{~h} 50$ & $38 \mathrm{~h} 25$ & 10.1 & 14.0 \\
\hline Ro & Romania & 4,387 & 3,289 & 25.0 & $43 \mathrm{~h} 00$ & $40 \mathrm{~h} 40$ & 4.8 & 21.3 \\
\hline Sk & Slovakia & 9,684 & 7,511 & 22.4 & $43 \mathrm{~h} 15$ & 40h00' & 7.7 & 15.9 \\
\hline $\mathrm{Si}$ & Slovenia & 20,968 & 19,242 & 8.2 & $42 \mathrm{~h} 15$ & 40h25' & 4.5 & 3.9 \\
\hline Es & Spain & 27,001 & 20,488 & 24.1 & $43 \mathrm{~h} 00$ & $37 \mathrm{~h} 05$ & 13.6 & 12.2 \\
\hline Se & Sweden & 42,061 & 30,802 & 26.8 & $36 \mathrm{~h} 55^{\prime}$ & 30h10' & 18.3 & 10.4 \\
\hline UK & United Kingdom & 43,650 & 24,800 & 43.2 & $42 \mathrm{~h} 40^{\prime}$ & $32 \mathrm{~h} 40^{\prime}$ & 23.4 & 25.8 \\
\hline
\end{tabular}

* For non Euro-area countries, earnings are converted into Euros.

Authors' calculation on weighted data from EU-SILC 2008, rev. 4. Cross-sectional weights used. 
workers. Similar conclusions can be drawn when we substitute hourly pay gap with annual earnings gap. It is also interesting to discuss the relationship between employment rate and hours worked gaps (Figure 2) and how it varies by age group. For the total population there is no correlation between gaps in employment and in hours of work. However, this absence of correlation hides a strong negative correlation for younger workers and a strong positive correlation for the 30-54 year old group, indicating different behaviors of male and female workers as they age. These preliminary results confirm the importance of age in shaping labor market dynamics. Our analysis seeks to understand the different ways in which age affects labor market outcomes across European countries. It is well-documented that in many areas age does not have a monotonic relationship with other variables (Deshpande and Suresh, 1990). Therefore, for each country and for each labor market outcome, age profiles are analyzed by concentration curves that make it possible to estimate local changes in regression slopes, within the Gini regression framework. The next section outlines the main features of our methodology.

\section{A brief review of the methodology}

Our methodology uses concentration curves within a Gini regression framework (Yitzhaki and Schechtman, 2013) to study the relationship between two variables $Y$ and $X$ through visual tools. One of the main advantages of these curves is the possibility to graphically check whether the relationship between $Y$ and $X$ is monotonic over the entire range of the explanatory variable $X$. More generally, it allows one to distinguish within the overall regression coefficient the contribution of different sections of the explanatory variable.

\subsection{NLMA curves and Gini regression}

A concentration curve can be viewed as an extension of the Lorenz curve to include a two-variable case. The idea behind it is similar to that of the absolute or generalized Lorenz curve (Shorrocks, 1983), but in this case the horizontal axis and the vertical axis represent two different variables. Similarly to the presentation of Gini by a Lorenz curve, it is possible to use a concentration curve, the so called (N)LMA curve, to graphically present the Gini regression coefficient. The NLMA curve is the Normalized LMA (Line of independence Minus the Absolute concentration curve) curve, defined as the the Line Of Independence (LOI) minus the Absolute Concentration Curve (ACC) of $Y$ with respect to $X$. The ACC portrays on the horizontal axis the cumulative distribution of the explanatory variable $X$ and on the vertical axis the correspondent expected cumulative values of the dependent variable $Y$; while the LOI describes the expected cumulative values of $Y$ when $X$ and $Y$ are independent. The properties of 
Figure 1: Gender gaps across European countries 2008: hourly earnings gap versus employment rate gap. A small amount of random noise (jittering, Gelman et al., 1995) is added to the points, to make any multiplicities transparent. The dotted lines are regression lines fit to the observed data.
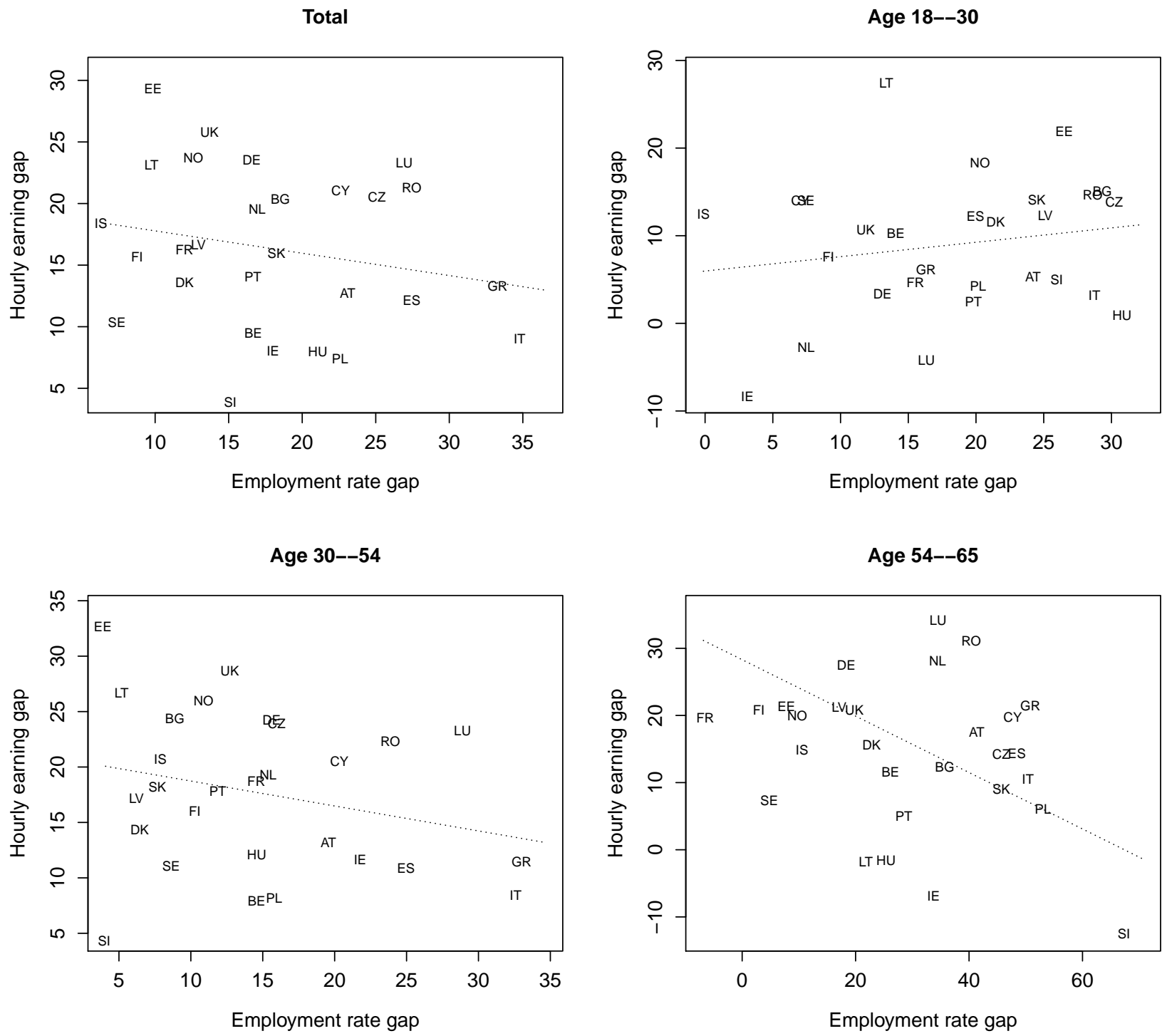
Figure 2: Gender gaps across European countries 2008: gap in hours of work versus employment rate gap. A small amount of random noise (jittering, Gelman et al., 1995) is added to the points, to make any multiplicities transparent. The dotted lines are regression lines fit to the observed data.
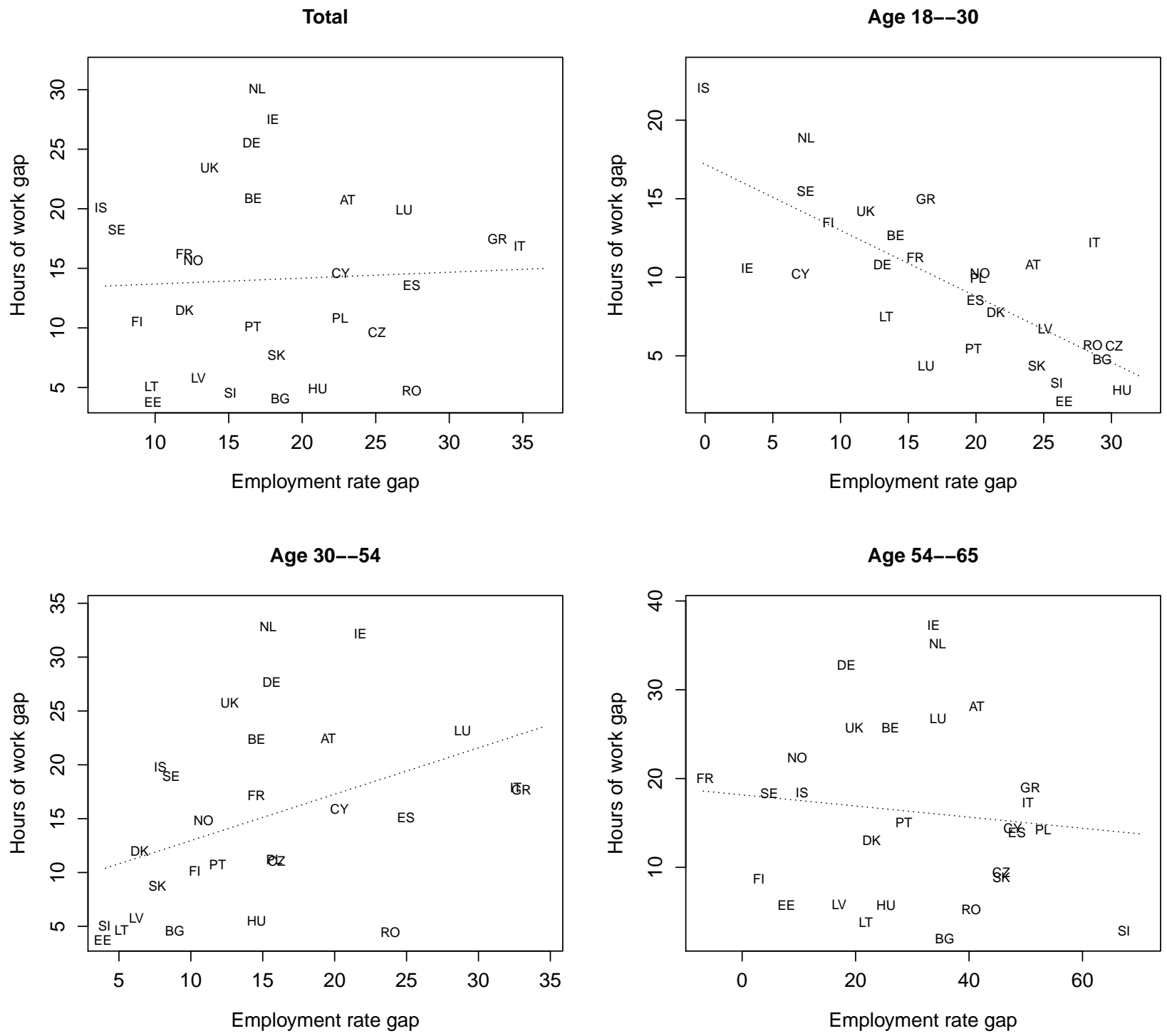
the ACC are useful in several areas. ${ }^{5}$ In the area of regression there are two potential uses for concentration curves. The first is to investigate how the association between two variables changes along the range of the explanatory variable and the second use is to study the weighting scheme of the regression curve (see Heckman et al., 2006, for the derivations of the weighting schemes for many different econometric models). In this paper we concentrate on the first use.

Let $g(x)=E(Y \mid X=x)$ be the conditional expectation of $Y$ given $X$, that is the regression curve. The Absolute Concentration Curve (ACC) of $Y$ with respect to $X$ can be formally defined as:

$$
\operatorname{ACC}(p)=\int_{-\infty}^{x_{p}} g(t) d \mathrm{~F}(t)
$$

where $x_{p}$ is implicitly defined by $p=\mathrm{F}\left(x_{p}\right)$, and $F$ is the cumulative distribution function of $X$.

In case of independence between $Y$ and $X$ the ACC curve collapses to the Line Of Independence (LOI) equal to:

$$
\operatorname{LOI}(p)=\mu_{Y} \times p
$$

where $\mu_{Y}$ the expected value of the dependent variable $Y$.

The LMA curve is defined as the difference between these two curves:

$$
\operatorname{LMA}(p)=\operatorname{LOI}(p)-\operatorname{ACC}(p)
$$

The properties of the LMA curve that are useful in our context are the following:

a) The LMA curve starts at $(0,0)$ and ends up at $(1,0)$. It can take any shape depending on properties of $g(x)=\mathrm{E}(Y \mid X=x)$.

b) The derivative (slope) of the LMA curve with respect to $p$ is equal to:

$$
\frac{d(\operatorname{LMA})}{d p}=\mu_{Y}-g\left(x_{p}\right) .
$$

As a consequence, the LMA curve has a positive (null, negative) slope if $\mu_{Y}$ is greater (equal, smaller) than $g\left(x_{p}\right)$.

c) The second derivative of the LMA curve with respect to $p$ is equal to:

$$
\frac{d^{2}(\mathrm{LMA})}{d^{2} p}=-\frac{d\left(g\left(x_{p}\right)\right)}{d p}=-\frac{d\left(g\left(x_{p}\right)\right)}{d x_{p}} \times \frac{d\left(x_{p}\right)}{d p} .
$$

As a consequence, the LMA curve is concave at $p$ (convex, straight line) if and only if $\frac{d\left(g\left(x_{p}\right)\right)}{d x_{p}}$ is greater (smaller, equal) than 0 , being $\frac{d\left(x_{p}\right)}{d p}$ always positive.

\footnotetext{
${ }^{5}$ For a comprehensive set of definitions and properties of the Absolute Concentration Curves, see Yitzhaki and Olkin (1991). For their use in in performing statistical analyses compatible with stochastic dominance in the area of tax reforms and in finance, see Yitzhaki and Schechtman (2013).
} 
d) The area between the LMA curve and the horizontal axis is equal to cov $(Y, \mathrm{~F}(X))$ (see Yitzhaki, 2003, for a formal proof). This property implies a direct relationship with the Gini regression coefficient, defined as (Olkin and Yitzhaki, 1992):

$$
\beta^{\mathrm{G}}=\frac{\operatorname{cov}(Y, \mathrm{~F}(X))}{\operatorname{cov}(X, \mathrm{~F}(X))}
$$

e) If the LMA intersects the horizontal axis, then there exist monotonic increasing transformations of $X$, that can change the sign of the regression coefficient in an OLS regression but not in a Gini regression.

By dividing the LMA curve by $\operatorname{cov}(X, \mathrm{~F}(X))$ the area enclosed between the curve and the horizontal axis becomes equal to the Gini regression coefficient. This curve is referred to as the Normalized LMA (NLMA) curve. The covariance cov $(X, \mathrm{~F}(X))$ is (one forth of) the well known Gini's mean difference (GMD) introduced by Gini in 1912.

The upper panel of Figure 3 illustrates the NLMA curve for a linear regression curve, while the bottom panel shows the NLMA for a piecewise regression curve. If $Y$ is a linear function of $X$, the LMA curve looks like a bell curve with the peak at the median. On the left-hand side of the figure the curve is increasing, an indication that the dependent variable is below its average, while on the right-hand side of the figure the curve is declining, which indicates that $Y$ is above its average. Since the linear relationship is always positive, the total regression coefficient is positive and the NLMA curve is always above the horizontal axis. A linear regression curve with a negative slope will result in a mirror image NLMA curve that will be always below the horizontal axis.

The bottom panel presents instead a segmented linear regression curve in which the first local regression coefficient is positive and the second is negative. This behavior is reflected in the corresponding LMA curve that changes curvature from concavity to convexity. The curve crosses the horizontal axis, therefore the sign of $\operatorname{cov}(Y, \mathrm{~F}(X))$ (and consequently the sign of the regression coefficient) depends on the magnitudes of the areas above and below the horizontal axis. The inspection of the NLMA curve allow for the decomposition of the Gini regression coefficient into intra- and inter- group components as we will illustrate in the next Section.

\subsection{Making up the regression coefficients}

Assume that observations are partitioned into $M$ disjoint (non-overlapping) groups, according to different levels of $X$, denoted by $m=1, \ldots, M$. Let $\pi_{m}=n_{m} / n$ be the relative size of group $m$ and $\bar{Y}_{m}$ and $\bar{X}_{m}$ the group's averages. The Gini regression 
Figure 3: Examples of NLMA curves.
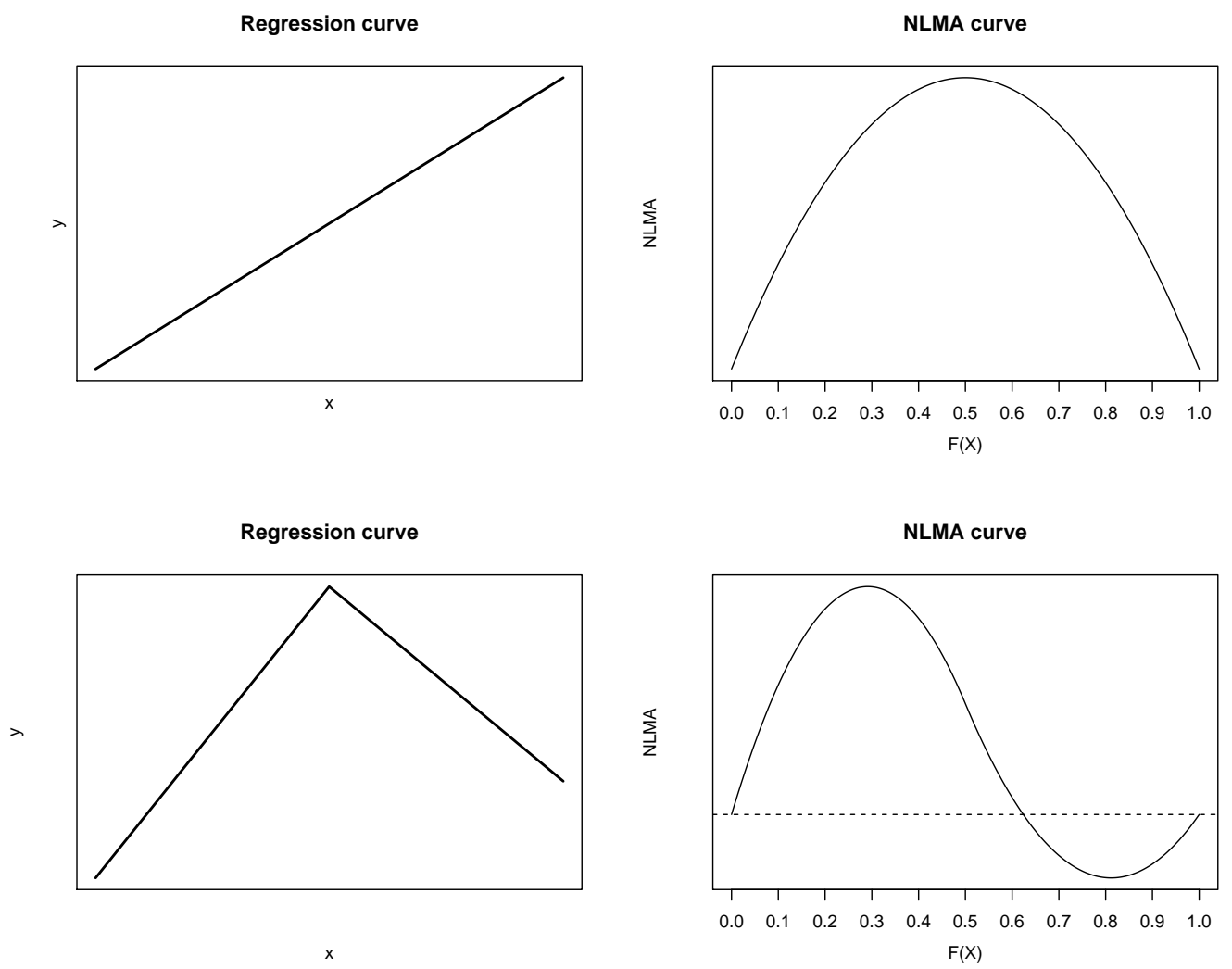

coefficient $\beta^{G}$ of the overall population can be decomposed as follows (Yitzhaki and Schechtman, 2013): ${ }^{6}$

$$
\beta^{G}=\sum_{m=1}^{M} w_{m} \beta_{m}^{G}+w_{B} \beta_{B}^{G} .
$$

This decomposition is based on four types of components: the group's weight $\left(w_{m}\right)$, the group's regression coefficient $\left(\beta_{m}\right)$, the between-group weight $\left(w_{B}\right)$ and the betweengroup regression coefficient $\left(\beta_{B}\right)$. The first term of the right hand side of equation (5) can be interpreted as the intra (within)-group component, while the second term is the inter (between)-group component.

The term $w_{m}$ is the contribution of group $m$ to the overall variability and it is defined as $w_{m}=\pi_{m} \frac{G_{m}}{G}$. The term $G_{m}$ is (one forth of) the GMD of $X$ in group $m$ while $G$ is (one forth of) the GMD of $X$. The term $w_{B}$ is defined as

$$
w_{B}=\frac{\operatorname{cov}(\bar{X}, \overline{\mathrm{F}}(X))}{\operatorname{cov}(X, \mathrm{~F}(X))}
$$

where $\overline{\mathrm{F}}(X)$ is the vector of the $M$ averages of the ranks of the members of the groups when they are ranked according to the distribution of $X$. The coefficients $\beta_{m}^{G}$ and $\beta_{B}^{G}$

\footnotetext{
${ }^{6}$ The decomposition of the OLS regression coefficient follows the same structure, except that the weights are derived from the decomposition of the variance.
} 
are defined as follows:

$$
\begin{aligned}
& \beta_{m}^{G}=\frac{\operatorname{cov}_{m}(Y, \mathrm{~F}(X))}{\operatorname{cov}_{m}(X, \mathrm{~F}(X))} \\
& \beta_{B}^{G}=\frac{\operatorname{cov}_{B}\left(\bar{Y}_{m}, \overline{\mathrm{F}}(X)\right)}{\operatorname{cov}_{B}\left(\bar{X}_{m}, \overline{\mathrm{F}}(X)\right)} ;
\end{aligned}
$$

A similar decomposition holds also for the OLS regression coefficient. However, we focus on the Gini regression given its direct relationship with NLMA curves. ${ }^{7}$

\section{Analysis of age profiles by gender}

\subsection{Evidence from the NLMA curves}

Appendix A provides, for each country, men's and women's estimated NLMA curves by age for the following labor economic variables: employment rate, hours of work, annual and hourly earnings. ${ }^{8}$ At the risk of oversimplifying, we classify countries according to similar patterns of the NLMA curves. It turns out that with few exceptions, similarity in age patterns reflects geographical proximity. Table 3 shows the classification of the countries along with the main characteristics in terms of age profiles.

The first group of countries includes Sweden, Norway, Denmark and Iceland, all the Nordic countries but Finland. Although some differences exist, this group is characterized by similar estimated employment profiles. Employment increases with age for both men and women with a peak at around $20 \%$ of the age distribution (corresponding to late twenties/early thirties depending on the country) and essentially plateauing after that until it starts decreasing at around 85\%, which roughly corresponds to the pre-retirement age. Wage profiles, both in terms of total income and in terms of pay per hour, are also similar between men and women. The NLMA curves indicates that men's and women's earnings are expected to increase until their mid to late forties, after which they tend to settle. Obviously it is difficult to establish how age itself affects earnings because of convolution of age, cohort and selection effects. Therefore, any evidence can be interpreted only as suggestive of relevant association rather than to reach firm conclusions. With the exception of Iceland, the remarkable difference between men and women in this group occurs in NLMA curves of weekly hours of work. Men's working hours over life course tend to assume an inverse U-shaped distribution. This is revealed by the alternance between concave and convex regions. On the other hand, women's hours of work show striking variation over the life cycle eventually forming

\footnotetext{
${ }^{7}$ Note also that a monotonic transformation of the explanatory variable, $X$ does not affect $F(X)$. Therefore, unlike the OLS, a monotonic transformation of $X$ cannot change the sign of the Gini regression coefficient but only may affect its magnitude (see last property of LMA curves). On the properties of the Gini regression and its advantages see Yitzhaki and Schechtman (2004).

${ }^{8}$ All the computing was done with R (R Development Core Team, 2012).
} 
Table 3: Classification of the countries in terms of their age profiles characteristics.

\begin{tabular}{|c|c|c|}
\hline Group & Countries & Age profiles characteristics \\
\hline 1 & $\begin{array}{l}\text { Denmark } \\
\text { Iceland } \\
\text { Norway } \\
\text { Sweden }\end{array}$ & $\begin{array}{l}\text { Labor participation profile for men and women almost } \\
\text { identical. Very different profiles in hours of work for } \\
\text { men and women: inverse U-shape for men, M-shape for } \\
\text { women. Similar earnings profiles: increase until late } \\
\text { forties and settle later on. }\end{array}$ \\
\hline 2 & $\begin{array}{l}\text { Cyprus } \\
\text { Greece } \\
\text { Italy } \\
\text { Portugal } \\
\text { Spain }\end{array}$ & $\begin{array}{l}\text { Similar profile between men and women for earnings } \\
\text { (almost linear). Very different behavior in } \\
\text { participation and hours of work. }\end{array}$ \\
\hline 3 & $\begin{array}{l}\text { Austria } \\
\text { Belgium } \\
\text { Czech Republic } \\
\text { France } \\
\text { Germany } \\
\text { Ireland } \\
\text { Luxembourg } \\
\text { Netherlands } \\
\text { Slovakia } \\
\text { United Kingdom }\end{array}$ & $\begin{array}{l}\text { Similar age profiles in employment rate. Large } \\
\text { differences in terms of hours of work between men and } \\
\text { women. Earnings positively correlated with age for } \\
\text { men and weakly correlated for women. }\end{array}$ \\
\hline 4 & $\begin{array}{l}\text { Estonia } \\
\text { Finland } \\
\text { Latvia } \\
\text { Poland } \\
\text { Romania } \\
\text { Slovenia }\end{array}$ & $\begin{array}{l}\text { Similar age patterns by gender in all labor market } \\
\text { outcomes. }\end{array}$ \\
\hline 5 & $\begin{array}{l}\text { Bulgaria } \\
\text { Hungary } \\
\text { Lithuania }\end{array}$ & $\begin{array}{l}\text { Similar age patterns by gender in employment and } \\
\text { hours of work. Women age profiles in earnings } \\
\text { characterized by a dip during the thirties. }\end{array}$ \\
\hline
\end{tabular}


an M-shape distribution that reflects the decrease in working hours during periods of childbirth and childbearing.

Among the countries belonging to the first group, we selected Sweden. The choice of one country among others is not related to any theoretical fundamental but rather has the aim of enhancing the potential of the method and, in this vein, Sweden can be considered a representative country. Figure 4 shows NLMA curves of labor market variables by gender in Sweden. In each plot we added dotted lines for both men and women in order to connect the points which identify sub-intervals that make up the overall regression coefficient. The decomposition of the Gini regression coefficients will be explored in the next section.

Figure 4: NLMA curves of labor market outcomes by age and gender in Sweden.

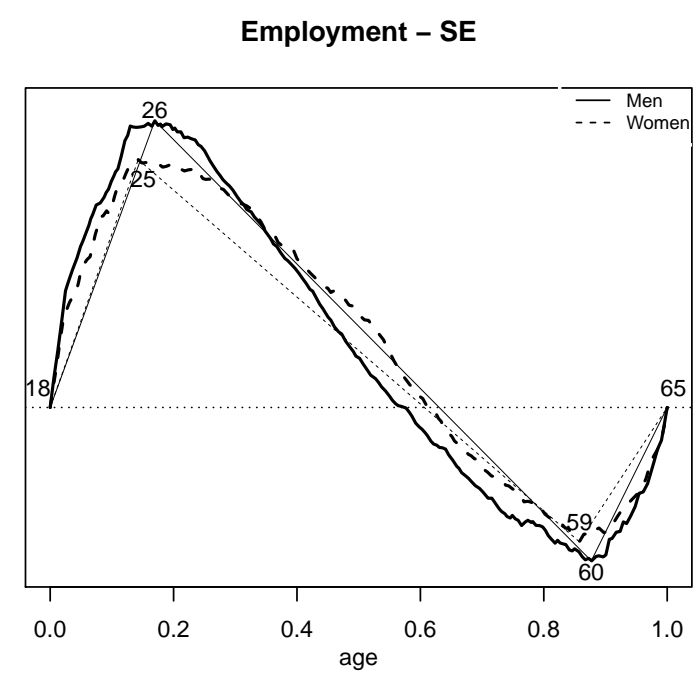

Annual earnings - SE

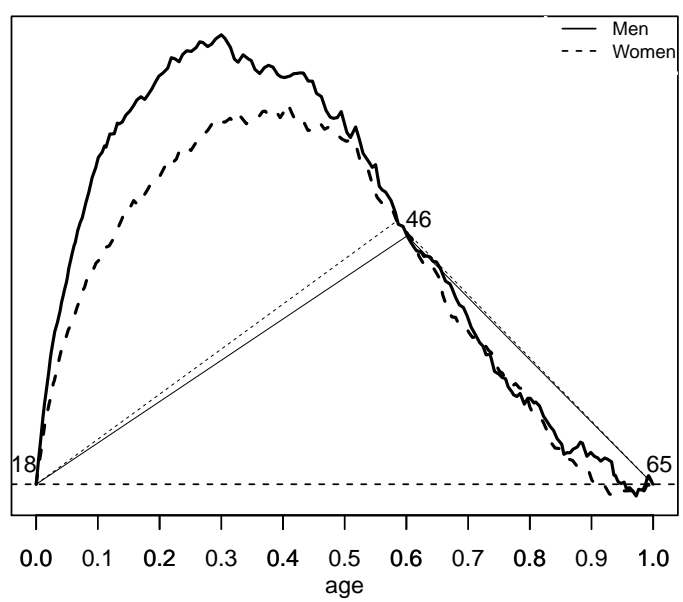

Hours of work - SE

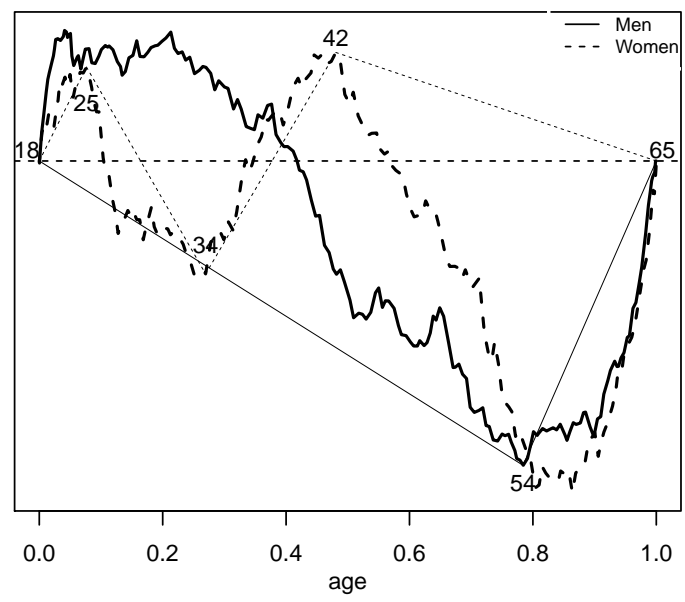

Hourly earnings - SE

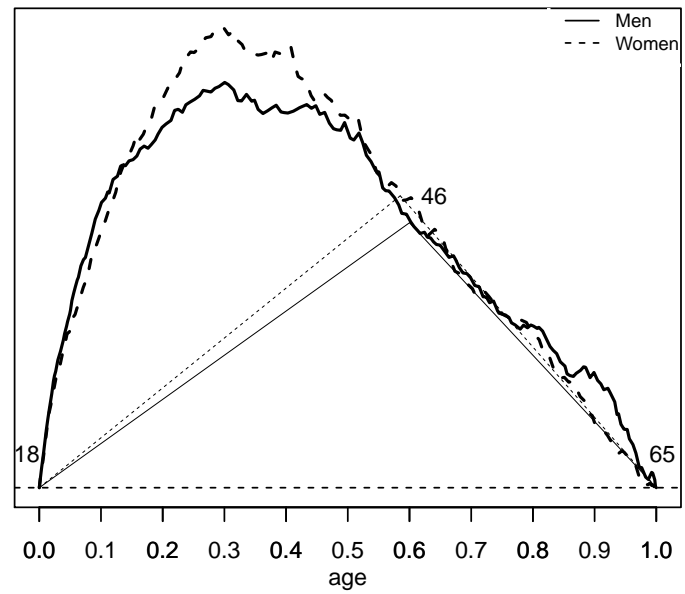

The second group of countries comprises Italy, Spain, Portugal, Greece and Cyprus. A common characteristic of these countries is the presence of a similar profile between 
men and women in regards to earnings, in contrast with a very different behavior in employment and hours of work. We picked Italy as the representative country for this group. Figure 5 shows the NLMA curves for this country. Although the pattern in employment for men and women looks the same, there are some important differences. To some extent, men seem to follow the "turning points" of women: for women aged 18-26 and 56-65 employment rate is below average, while male employment rate is below average for men aged 18-29 and 58-65 (ages that vary little among the countries in this groups). For middle-aged workers employment rate is quite stable for men (the NLMA curve is almost linear) and decreasing for women (the NLMA curve is slightly convex). This trend is particularly prominent in the case of Spain and Greece. The behavior of women in terms of hours of work is essentially the reverse of that of men. The estimated effect of age on hours of work is positive for men aged less than 35 (corresponding to the 25th percentile). After that, work effort starts to gradually decrease until the age of 50-55. For women the estimated effect of age is negative until the age of 35-40. After this, hours worked for women rise until pre-retirement age. The inverse U-shape of both the earnings NLMA curves indicates that men's and women's earnings are expected to constantly increase until the age of retirement, even though the upwards sloping is steeper for men than for women. This evidence may suggest that male and female workers are both protected by seniority rules, union bargaining and employment protection legislation. An alternative explanation would be that low wage employees tend to quit working at earlier age. These age-earnings profiles are in line with the theoretical framework developed by Lazear (1979), according to which the worker is initially underpaid - that is wage lower than his/her marginal productivity but later on in working life the worker is overpaid. Such delayed compensation contract discourages workers from "shirking" and this is true for both men and women. The decomposition of the Gini regression coefficients for Italy will be presented in the following section.

France, Germany, the Netherlands, United Kingdom, Luxembourg, Belgium, Austria and, to a lesser extent, Ireland, Czech Republic and Slovakia belong to a third group. Generally, labor participation profiles for men and women are almost identical (with the exception of Ireland and Czech Republic). Male and female employment rate increases with age, peaking at around $20 \%$ of the age distribution and remaining almost constant for middle-aged workers and then gradually decaying. Age appears to be more of a discriminating factor for working hours, where it amplifies large differences between male and female profiles. In terms of hours worked, men show small correlation with age, with the exception of France where a significant positive correlation is evident. With little differences among countries, men in this group work less than average when they are young, increase their work time until the early thirties and slightly decrease it until retirement. The variability in female working hours by age is more relevant: women work more than average when they are young. There is evidence of a significant 
Figure 5: NLMA curves of labor market outcomes by age and gender in Italy.
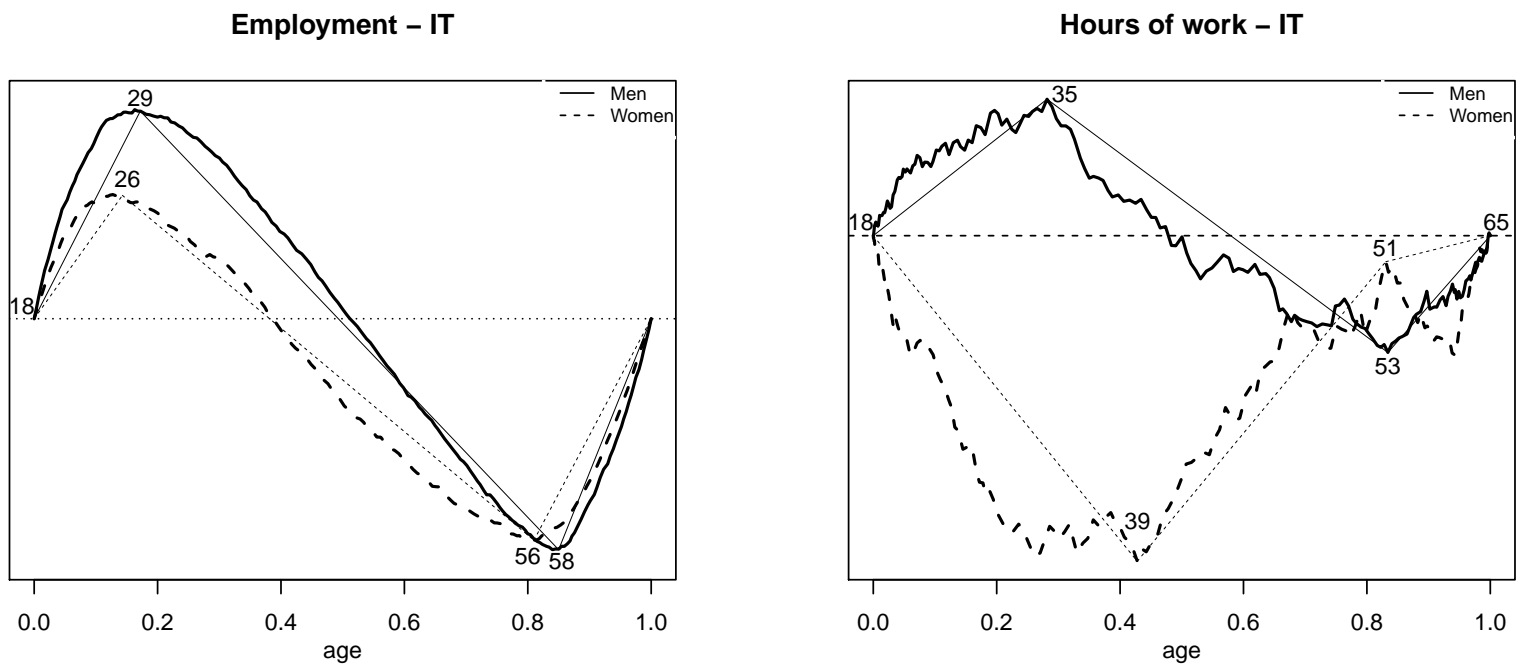

Annual earnings - IT
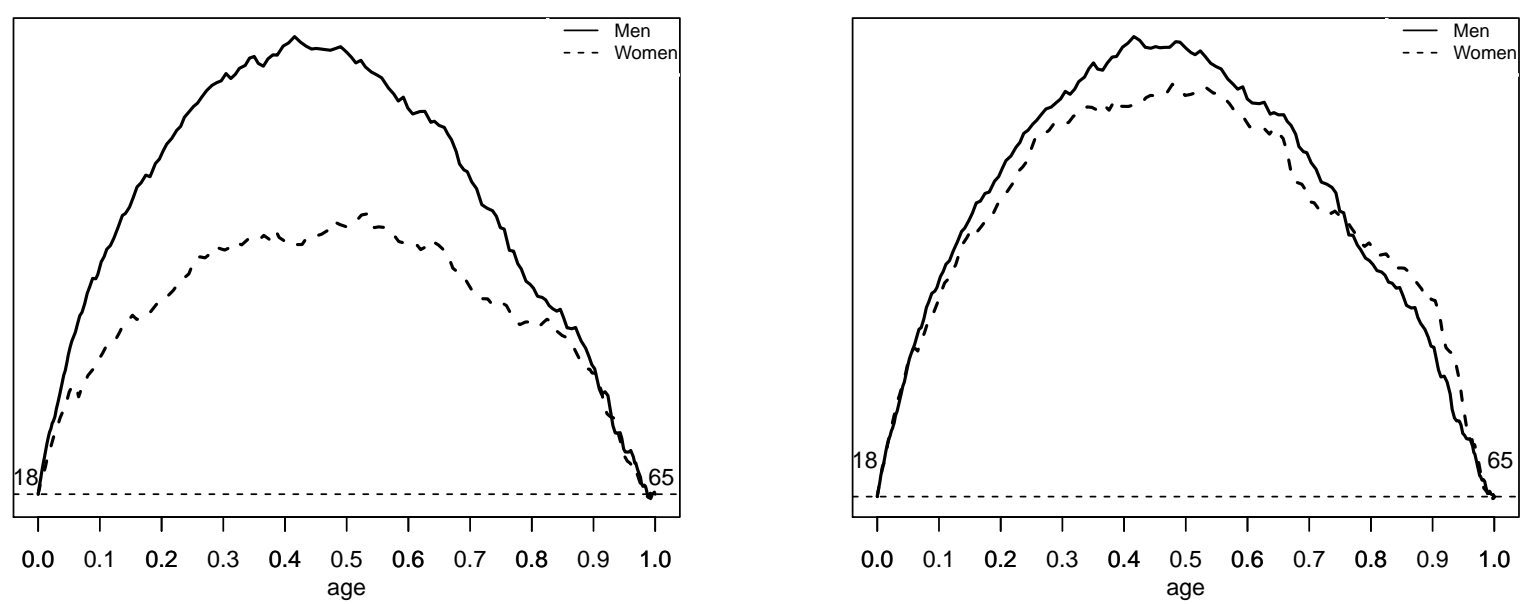
reduction in working hours for women in the thirties, which probably reflects cultural attitudes towards child rearing in these countries, as witnessed by the convexity in the curve. An increase in working hours is present for women in the 35-55 age group, followed by a substantial reduction for older female workers. The main feature of this group occurs in earnings profiles. The resultant picture for earnings shows them to be positively correlated with age for men and weakly correlated for women. Germany was selected as the representative country of this group (see Figure 6) and the Gini regression decomposition was performed on it.

Figure 6: NLMA curves of labor market outcomes by age and gender in Germany.

Employment - DE

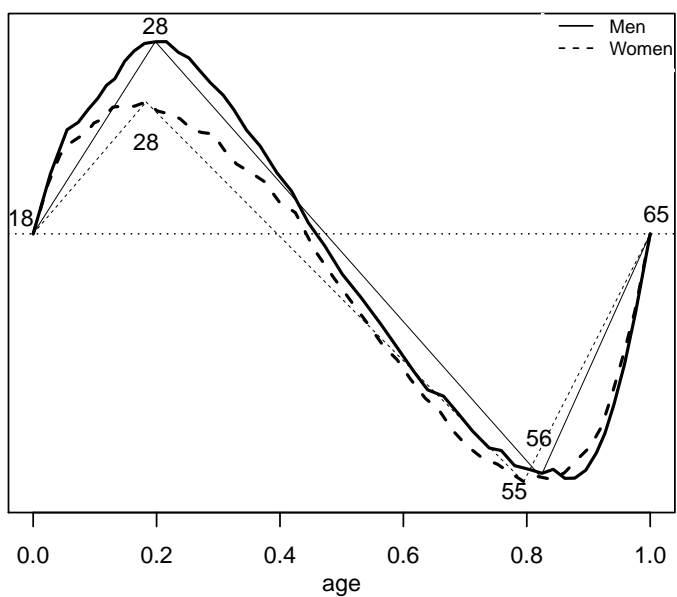

Annual earnings - DE

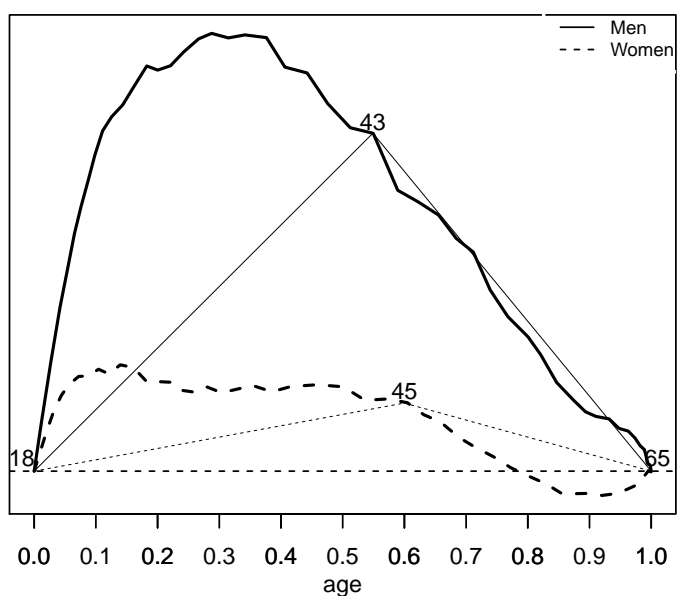

Hours of work - DE

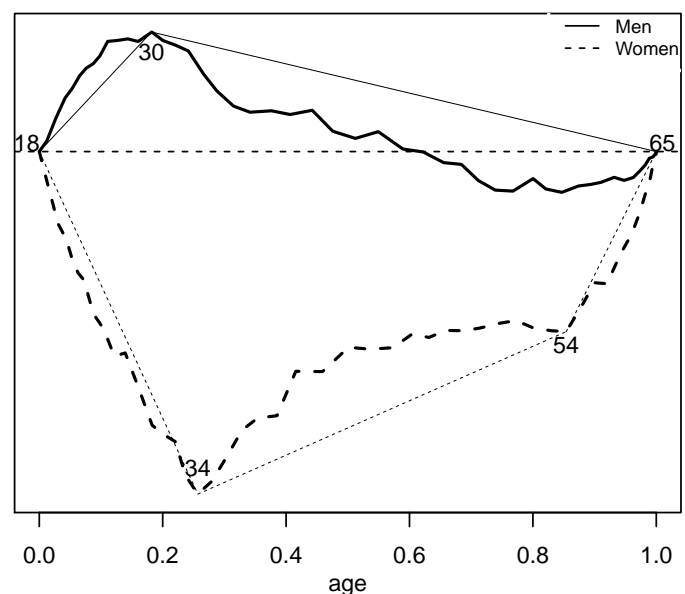

Hourly earnings - DE

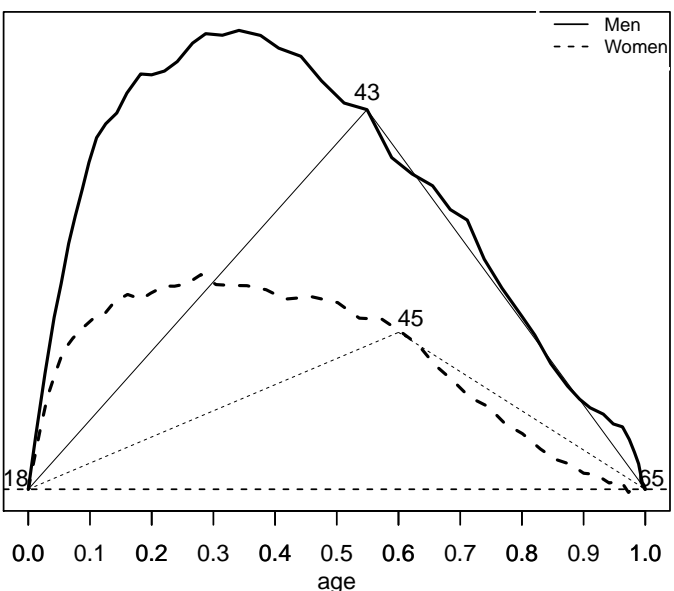

Another group of countries characterized by similar age patterns by gender in all labor market variables is comprised by Poland, Latvia, Estonia, Slovenia, Finland and Romania. The patterns are perhaps best illustrated by the case of Poland (see Figure 7). Male age profile for employment is close to women's profile and the same is true 
of the hours of work pattern. Male earnings are characterized by an initial rise for the lower $40 \%$ observations (up to age 35 in Poland) and then a gradual fall off. Female earnings behave in a somewhat similar manner, while showing a less substantial increase. For these countries, annual and hourly earnings profiles are in accordance with the profiles in working hours, with high positive correlation between wages and hours worked. This empirical evidence can be related, at least for the Eastern countries, to the employment structure, which is still more oriented towards manufacturing rather than advanced services.

Figure 7: NLMA curves of labor market outcomes by age and gender in Poland.

Employment - PL

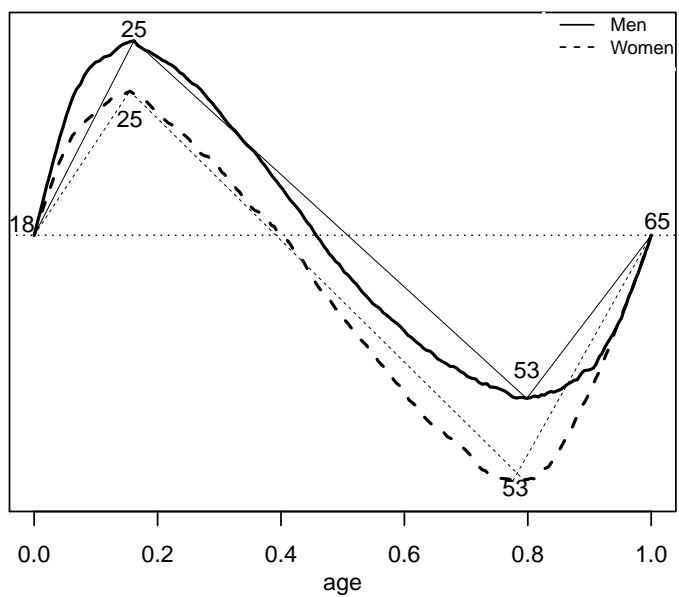

Annual earnings - PL

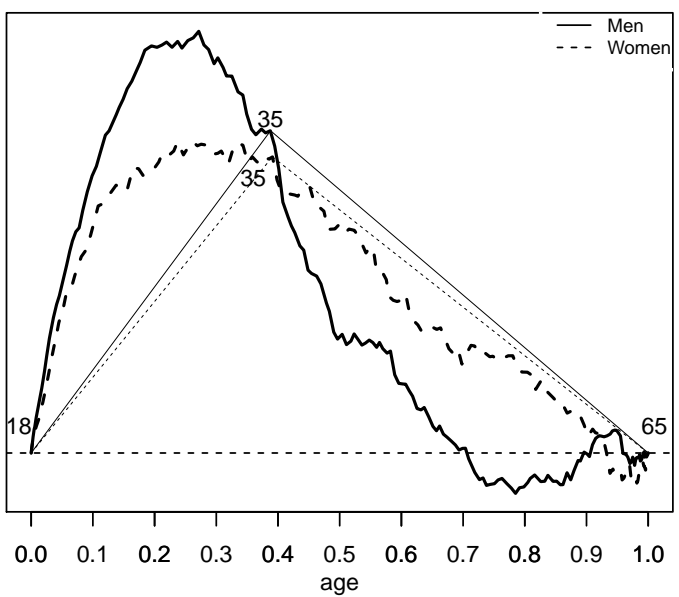

Hours of work - PL

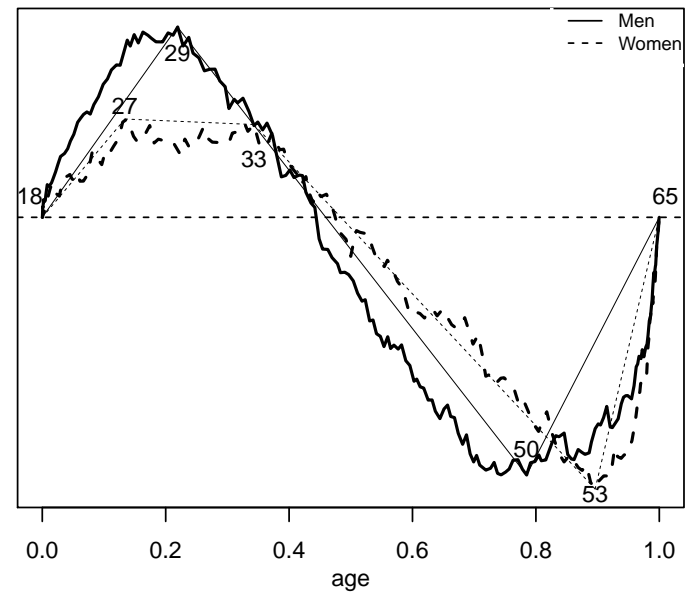

Hourly earnings - PL

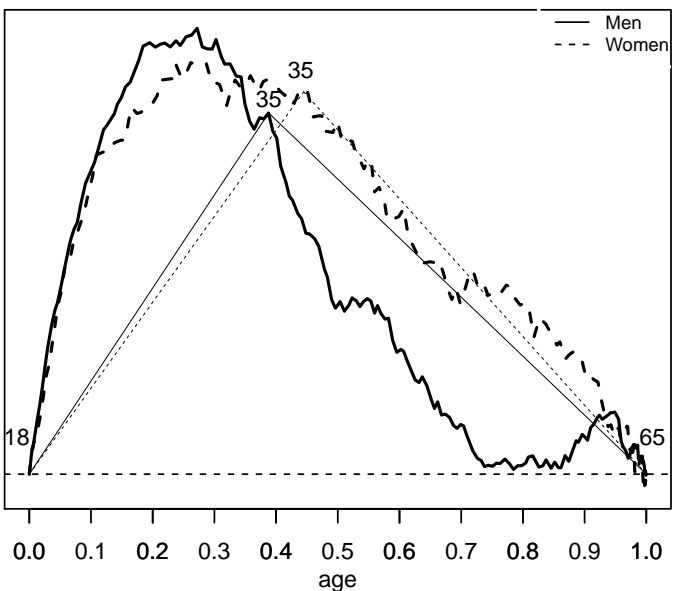

The last group comprises Lithuania, Bulgaria and Hungary. The distinctive feature of this group is essentially related to the earnings profile, which shows, for men, an increase until the thirties and then a gradual drop until retirement. In the case of women instead we have an initial increase, as shown by the concavity in the NLMA curve. 
The curvature then goes from concave to convex, which indicates a "dip" associated with the childbearing period, which is followed by a slight increase or by stability, until women leave the labor market. Lithuania is the representative country of this group. Figure 8 shows NLMA curves for Lithuania. As we can see, there is similarity in the employment patters of men and women. This similarity becomes more visible when we ignore minor differences due to small sample sizes in the NLMA curves.

Figure 8: NLMA curves of labor market outcomes by age and gender in Lithuania.
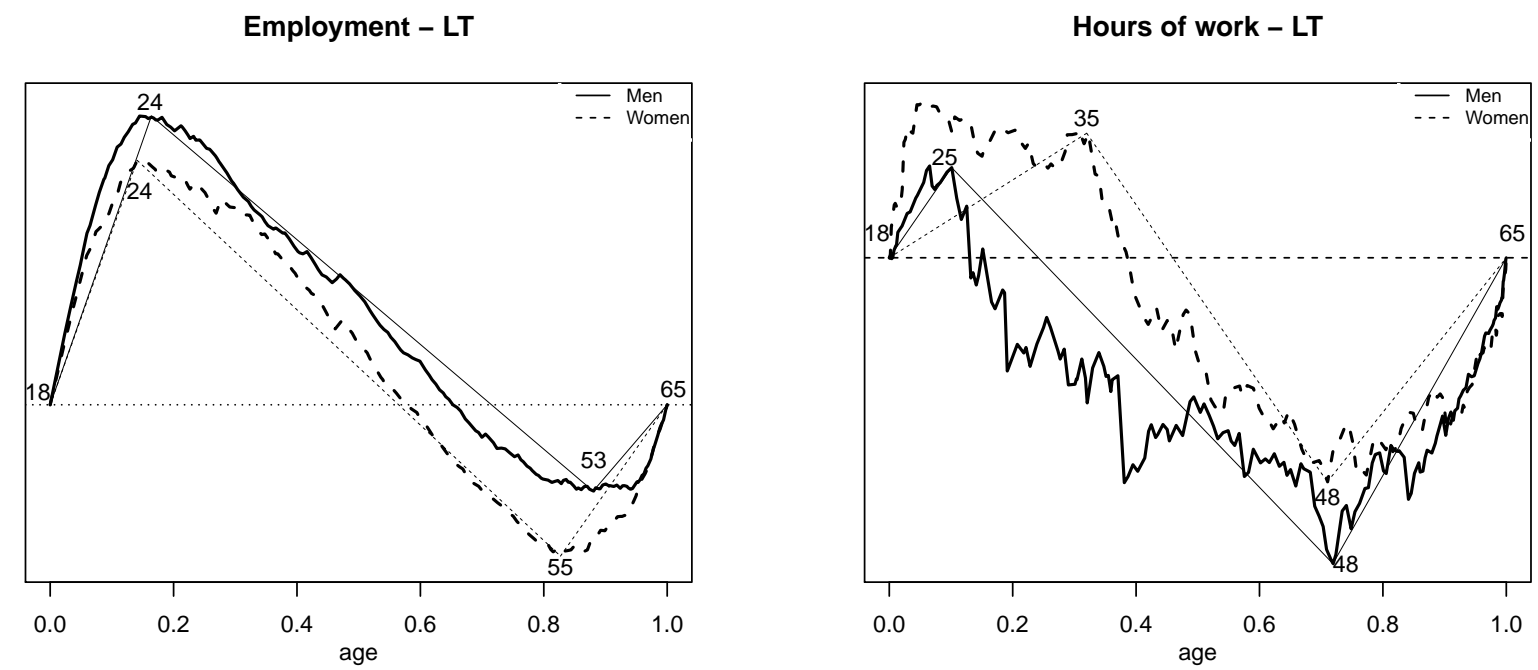

Annual earnings - LT

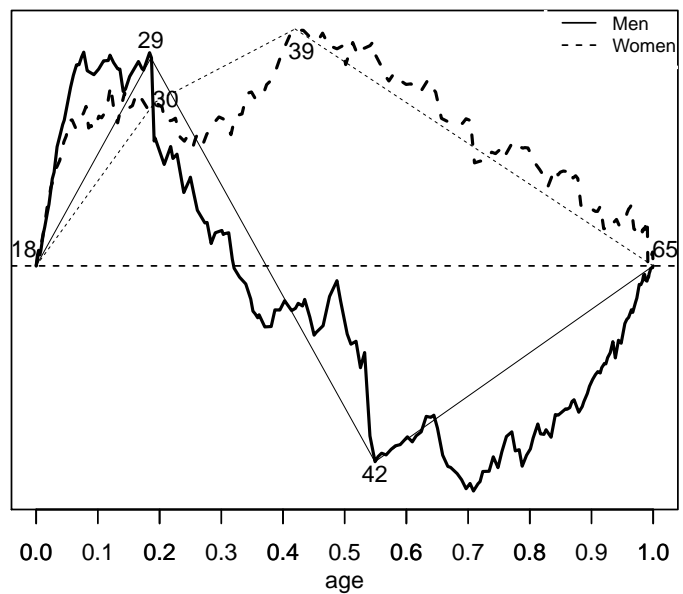

Hourly earnings - LT

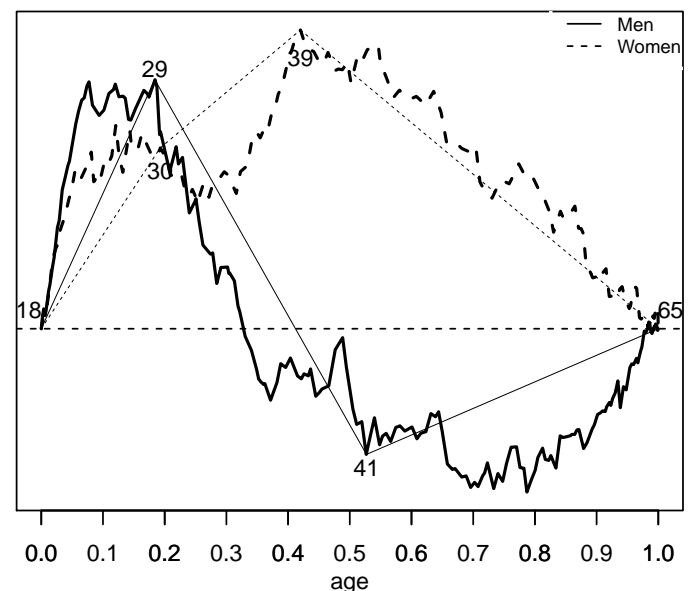

\subsection{Decomposition of the Gini regression coefficients}

In this section we try to "translate" what we have learned from the NLMA curves into the decomposition of non-overlapping age groups and their contribution to the overall 
Gini regression coefficients. ${ }^{9}$

We report the Gini decomposition, along with the ingredients for the regression "make up", for the five representative countries. ${ }^{10}$

Table B.1 presents the contributions of different age groups to the Gini regression coefficient for Sweden, according to the grouping identified by the NLMA curves as shown in Figure 4. In terms of employment rate, the expected annual increase is $7.4 \%$ for men and $6.2 \%$ for women until the ages of 26 and 25, respectively, and employment rate is below average. The estimated $\beta$ coefficient is equal to -0.14 for men aged $26-60$ and equal to 0.18 for women aged $25-59$, indicating a rather stable employment rate within those ranges, which is above average. After 60, the rapid increase of the NLMA curves (see upper left panel in Figure 4) translates into negative coefficients for both men and women accompanied with below average employment rate. The estimated $\beta$ coefficients of weekly hours of work is equal to 0.054 for men aged less than 54 years old (corresponding to $78 \%$ of the entire working men) and equal to -0.348 for the older group. This roughly means that men increase their effort at work by less than 5 minutes per year until the age of 54; after that the time weekly spent on work decreases at a pace of approximately 20 minutes per year. The Gini decomposition for women confirm the M-shape already detected by the NLMA curve corroborated by estimated alternative signs in the regression coefficients. The decomposition of annual earnings clearly shows an expected annual increase of 948 euros for men and 693 euros for women until the age of 46; after that age annual earnings for both men and women start to decrease at a rate of of 237 and 309 euros per year, respectively. In terms of hourly earnings the expected increase of 0.50 cent is similar for men and women until the age of 46 , followed by stability till retirement.

The Gini decomposition for Italy is presented in Table B.2. The most relevant features are: a significant reduction of $0.25 \%$ per year in the employment rate for women aged 26-56; the almost specular behavior of men and women in terms of working hours; and the linearity of annual and hourly earnings for both men and women.

The third group of European countries is represented by Germany, whose Gini regression decomposition is shown in Table B.3. What characterizes this group is essentially a different pattern for men and women in terms of working hours and earnings. On average, employed men annually increase their weekly working hours by about 20 minutes per year until the age of 30 . After that, they slightly reduce their working hours by 5 minutes a week per year. Women instead reduce their weekly hours at a rate of about 15 minutes per year until the age of 34, after which they increase it by about 6

\footnotetext{
${ }^{9}$ To check the robustness of our results we also run OLS regressions. The sign of all the regression coefficients are identical and the values do not differ significantly.

${ }^{10} \mathrm{~A}$ similar analysis has been performed for all the European countries but is not reported for sake of space. The results do not significantly differ across countries of same groups and are available upon request.
} 
minutes a week per year until the age of 54 and rapidly decrease it after that. Men's annual earnings increase by 1520 euros per year until the age of 43 in contrast with an increase of only 270 euros for women. A similar behavior is detected for hourly pay. Moreover, after the mid forties the reduction in annual earnings is much more pronounced for women than for men: 388 euros per year versus 113.

Poland represents the fourth group of European countries described above. Gini decomposition for Poland is shown in Table B.4. It confirms the close association between the annual earnings pattern and the working hours pattern for both men and women. Young men tend to increase their work hours by 15 minutes a week per year with a consequent increase in their annual earnings of 425 euros per year until the age of 35 . For young women, the increase in working hours is less pronounced (around 5 minutes a week) and thus the annual earnings are expected to increase less (about 250 euros per year). In contrast, age profiles for hourly pay of men and women are more similar, and the same holds for age - employment profiles.

Lithuania was selected as representative for the last group. As shown in Table B.5, the pattern of men annual earnings is compatible with the age-working hours profile. For men, an initial increase in both weekly hours and earnings when they are in their twenties is followed by a substantial stability until their forties and a moderate decrease after that. Women, instead, increase their earnings until 30 by a rate of about 300 euros per year, but in the 30-39 range their expected annual earnings decrease by 220 euros per year. Similarly, the estimated negative coefficient for hourly earnings $\left(\beta_{30-39}=-0.119\right)$ implies that each additional year of age corresponds to an expected reduction of 12 cents an hour. A slight increase in earnings is estimated as women reach 40 years old until retirement, despite a reduction in terms of hours of work.

\section{Conclusions and further research}

In the present paper we have used concentration curves within a Gini regression framework to represent European gender differences in labor market age profiles. The Line of independence Minus the Absolute concentration curve (NLMA) for each key variable in the labor market showed sections where the curves were convex and sections where they are concave. The Gini regression enabled us quantify the contribution of each section to the overall regression coefficient. This connection between Gini regression coefficients and concentration curves allowed us to verify the monotonicity of regression curves between age and employment rate and working hours, annual and hourly earnings. The search for a monotonic relationship is important because conclusions that are based on non-monotonic regression curve may be sensitive to the selection of the range of variables in the model and to monotonic transformation of the variables.

Based on the European Statistics on Income and Living Conditions (EU-SILC), we analyzed the European labor market age file in all the 28 countries covered by the 
survey in 2008. These countries were grouped based on similar behavior for a better interpretation. We detected five different groups according to their age patterns in the labor market. Generally country classification reflects geographical proximity with few exceptions: e.g. Finland does not belong to the group of the other Nordic countries; Lithuania is not in the same group with the other two Baltic states. For each group, a representative country was selected. For the selected countries, we first estimated the NLMA curve and then identified age sections that showed positive (or above average) slopes in the regression curve and sections with negative (or below average) values, so that adding up the slopes yielded the appropriate Gini regression coefficient. As a result we were able to identify turning points in labor market variables according to age, to outline age profiles according to gender and check whether patterns differed between men and women and/or across countries. Our results show that both gender and age carry important implications for labor market outcomes. Gender is a crucial factor differentiating participation in the labor market among workers, although employmentage profiles do not substantially differ between men and women in almost all the European countries. The most relevant differences in age profiles concern workinghours-patterns: some countries are characterized by an almost specular behavior in men and women; other countries instead show similar patterns. Generally, earnings increase with age for both men and women. However, local regression coefficients are not monotonic over the entire age range and can even be locally negative in some countries.

The methodology used in this paper allows one to decompose a simple regression coefficient. The main advantage of this method relies on graphical tools provided by the NLMA curves. Obviously, it is limited to bivariate analysis. As pointed out by Yitzhaki and Schechtman (2013), the methodology can be extended to deal with multiple regression. The regression coefficients in a multiple-regression framework are derived as solutions of sets of linear equations, with the simple regression coefficients serving as parameters in this set of equations. However, due to interaction effects, complications and complexities arise. In fact, transformations applied to an independent variable may affect also other regression coefficients sign either directly (i.e., through the change in the sign or magnitude of the simple regression coefficient) or indirectly (through the change in the correlations with other regression predictors). Multiple Gini regression represent a challenging topic for further research.

\section{References}

Barth, E., Røed M. and Torp, H. (2002). Towards a Closing of the Gender Pay Gap, European Commission Report, Oslo.

Blau, F.D. and Kahan, L.M. (1996). Wage Structure and Gender Earnings Differential: 
An International Comparison. Economica, 63, 29-62.

Blau, F.D. and Kahan, L.M. (2000). Gender Differences in Pay. Journal of Economic Perspective, 14 (4), 75-99.

Blau, F.D. and Kahan, L.M. (2003). Understanding International Differences in the Gender Pay Gap. Journal of Labor Economics, 21, 106-144.

Deshpande, J. V. and Suresh, R. P. (1990). Non-monotonic Ageing. Scandinavian Journal of Statistics, 17, 257-262.

European Commission (2006). A Roadmap for Equality Between Men and Women 2006-2010. EC, Brussels.

Eurostat (2009). Eurostat Community Statistics on Income and Living Condition, Study Documentation, Luxembourg.

Gelman, A., Carlin, B.P., Stern, H. and Rubin, D.B., (1995). Bayesian Data Analysis. Chapman \& Hall, London.

Heckman, J., Urzua, S. and Vytlacil, E. (2006). Understanding Instrumental Variables in Models with Essential Heterogeneity, Review of Economics and Statistics, 88, 389432.

Lazear, E. P. (1979). Why Is There Mandatory Retirement?. The Journal of Political Economy, 87, (6), pp 1261-1284.

Lee, S., McCann, D., and Messenger, J. C. (2007). Working Time Around the World: Trends in Working Hours, Laws and Policies in a Global Comparative Perspective. Geneva, Switzerland: International Labor Organization.

OECD (2002). Employment Outlook, OECD, Paris.

OECD (2012). OECD Family Database, OECD, Paris.

Olkin, I. and Yitzhaki, S. (1992). Gini Regression Analysis. International Statistical Review, 60, (2), 185-196.

Olivetti, C. (2008). Gender and the Labour Market: An International Perspective and the Case of Italy. Rivista di Politica Economica, V-VI, 3-32.

Olivetti, C., and Petrongolo, B. (2008). Unequal Pay or Unequal Employment? A Cross-Country of Gender Gaps. Journal of Labor Economics, 25, 621-654.

R Development Core Team (2012). R: A Language and Environment for Statistical Computing. R Foundation for Statistical Computing, Vienna, Austria. ISBN 3-90005107-0, URL http://www.R-project.org.

Schechtman, E. and Yitzhaki, S. (1987). A Measure of Association Based on Gini's Mean Difference, Communications in Statistics: Theory and Methods, A16 (1), 207231. 
Shorrocks, A.F. (1983). Ranking Income Distribution. Economica, 50, 3-17.

Yitzhaki, S. (2003). Gini's Mean Difference: A Superior Measure of Variability for Non-normal Distributions, Metron, LXI, 2, 285-316.

Yitzhaki, S. and Olkin, I. (1991). Concentration Indices and Concentration Curves, in Karl Mosler and Marco Scarsini (eds.) Stochastic Orders and Decisions under Risk, Institute of Mathematical Statistics: Lecture-Notes Monograph Series, 19, 380-392.

Yitzhaki, S. and Schechtman, E. (2004). The Gini Instrumental Variable, or the "Double Instrumental Variable“ Estimator, Metron, LXII, 3, 287-313.

Yitzhaki, S. and Schechtman, E. (2012). Identifying Monotonic and Non-monotonic Relationships. Economics Letters, 116, 23-25.

Yitzhaki, S. and Schechtman, E. (2013). The Gini Methodology: A Primer on a Statistical Methodology. Springer, New York. 
A NLMA curves of labor market outcomes by age and gender in the European countries

A.1 First group: Denmark, Iceland, Norway, Sweden

Denmark
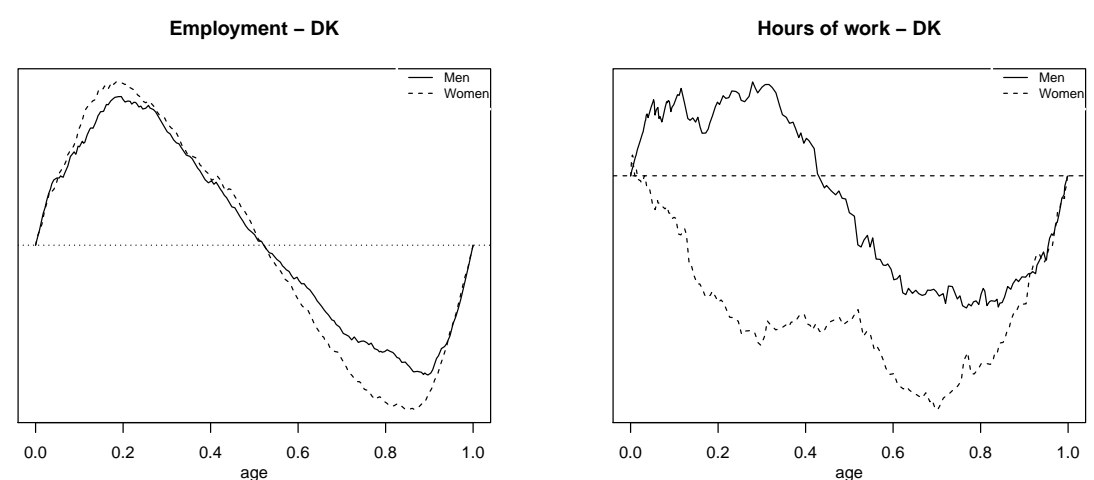

Annual earnings - DK

Hourly earnings - DK
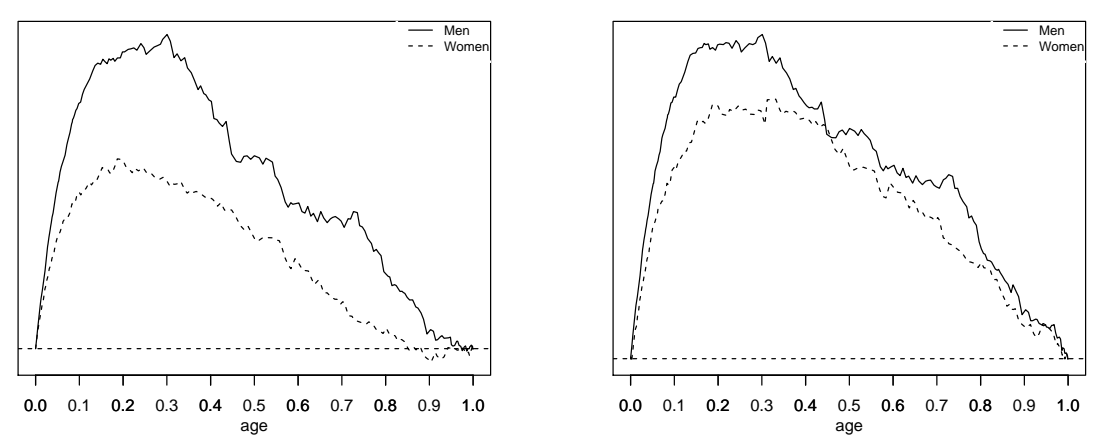


\section{Iceland}
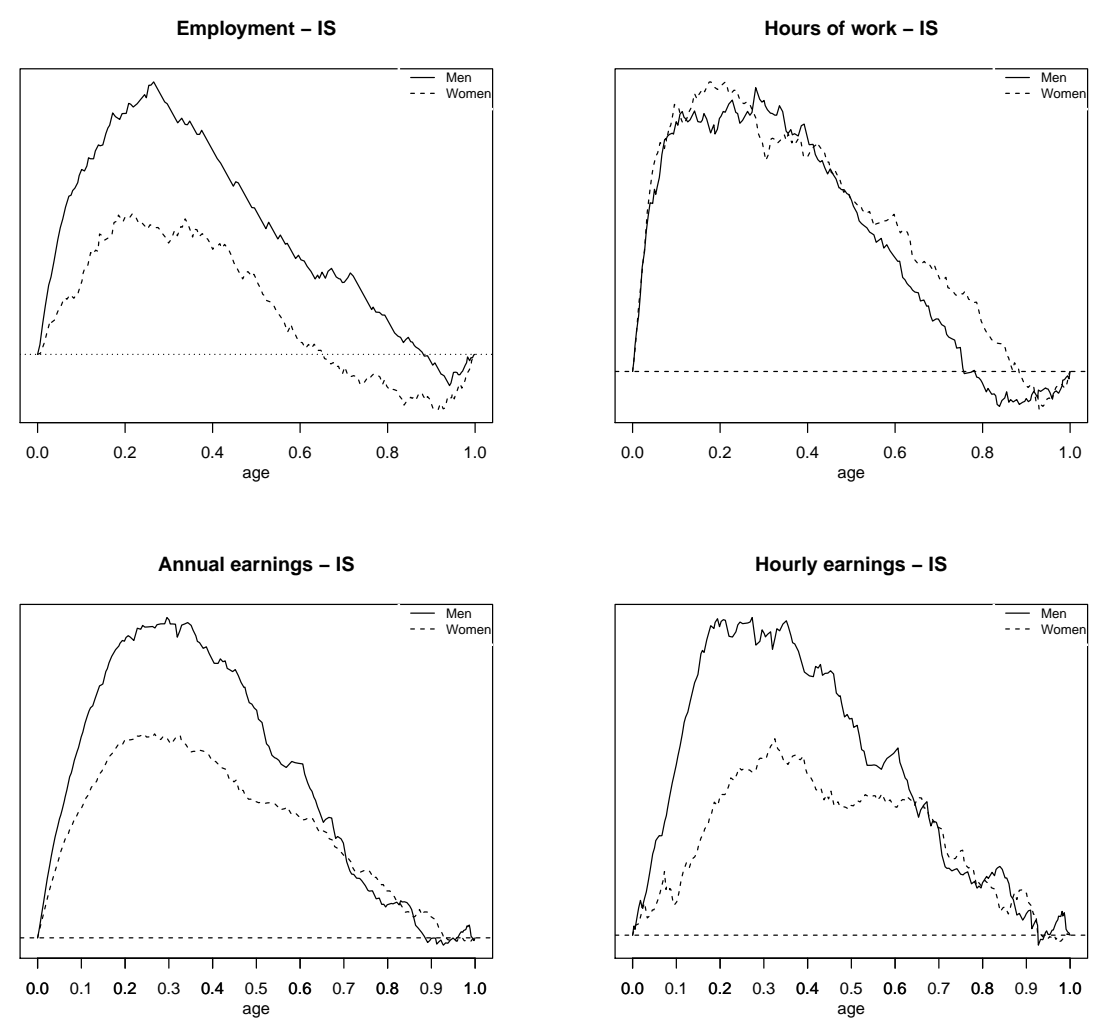

$\begin{array}{lllllllllll}0.0 & 0.1 & 0.2 & 0.3 & 0.4 & \begin{array}{c}0.5 \\ \text { age }\end{array} & 0.6 & 0.7 & 0.8 & 0.9 & 1.0\end{array}$

\section{Norway}
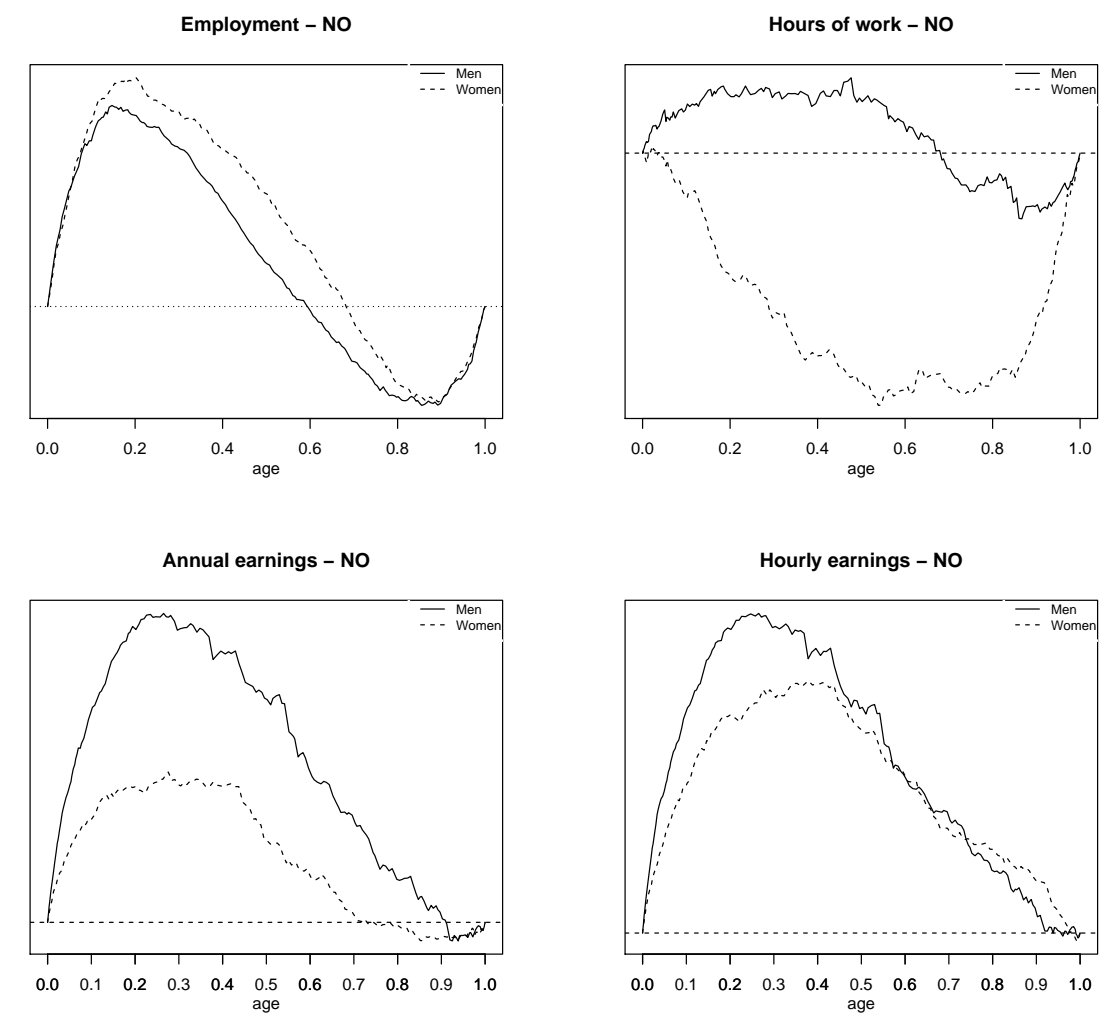
Sweden
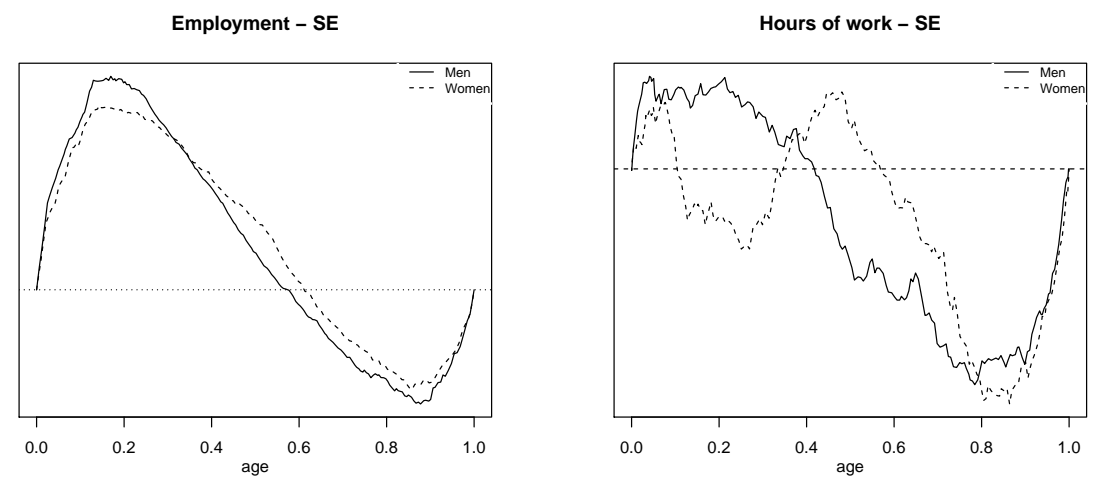

Annual earnings - SE

Hourly earnings - SE

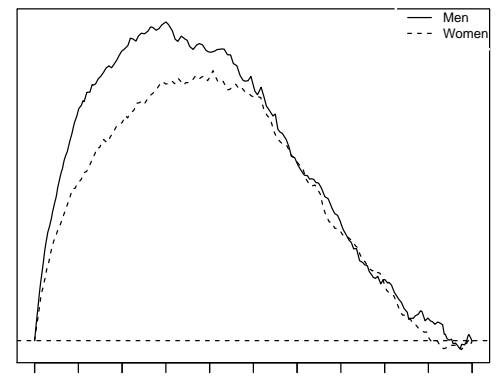

$\begin{array}{lllllllllll}0.0 & 0.1 & 0.2 & 0.3 & 0.4 & 0.5 & 0.6 & 0.7 & 0.8 & 0.9 & 1.0\end{array}$

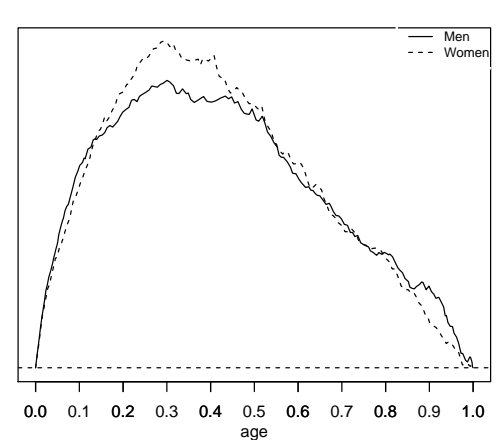


A.2 Second group: Cyprus, Greece, Italy, Portugal, Spain.

Cyprus
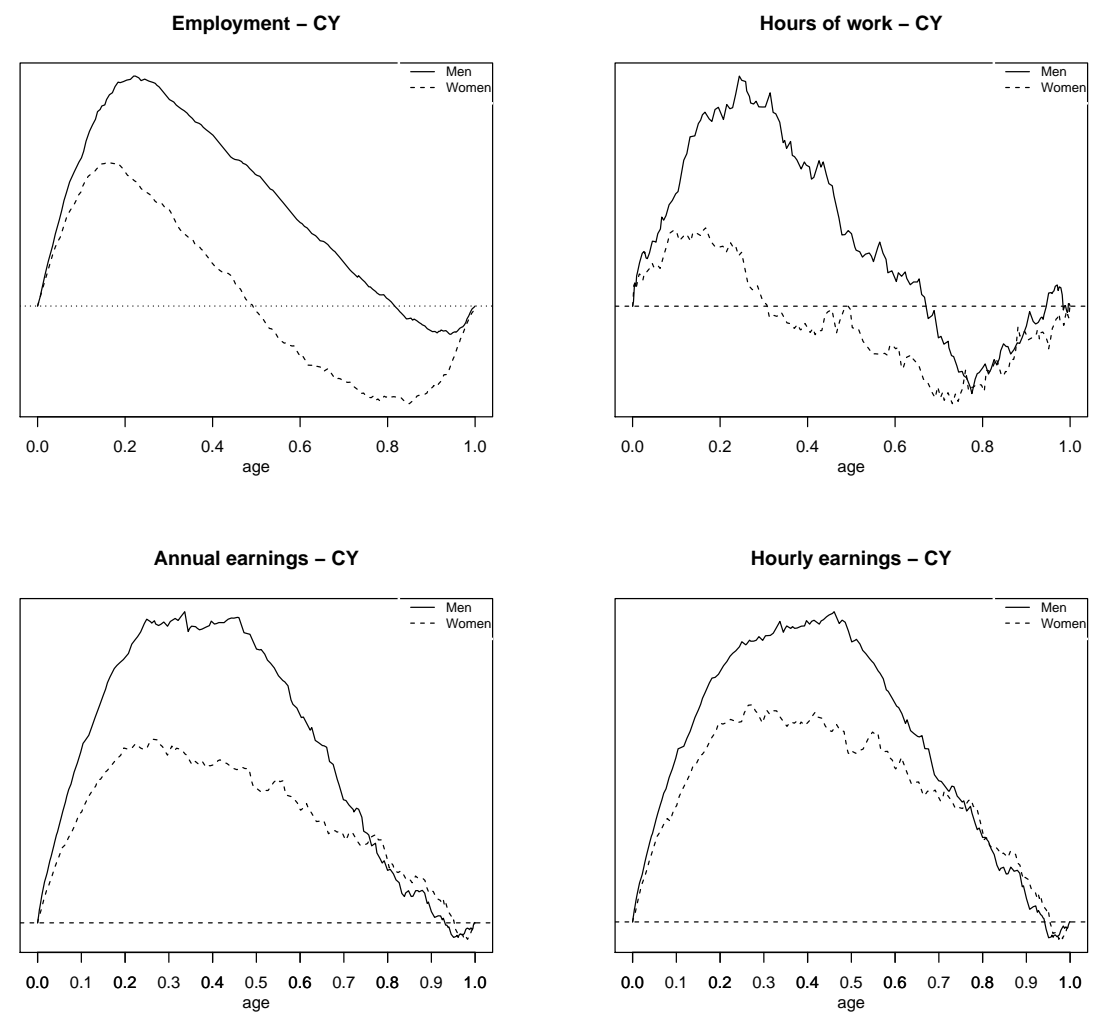


\section{Greece}
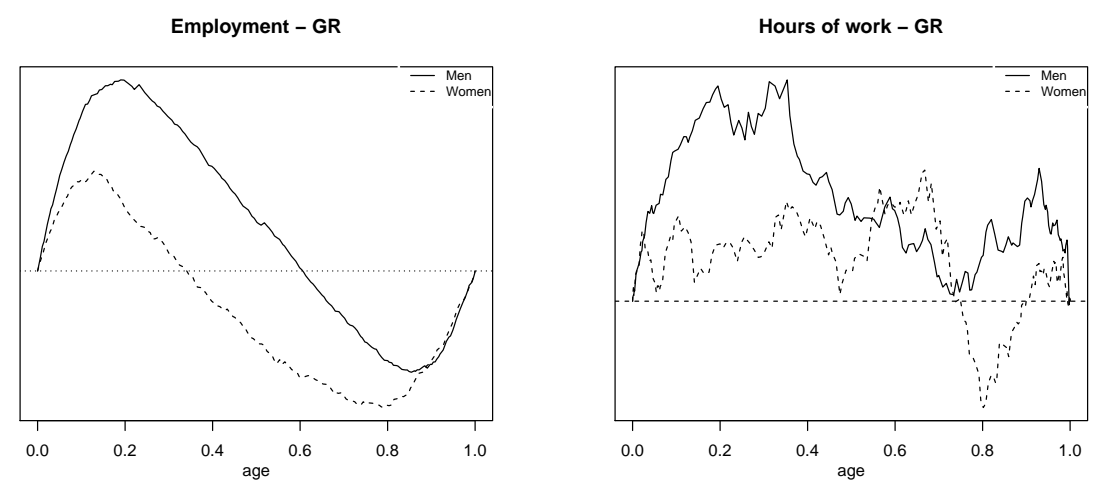

Annual earnings - GR

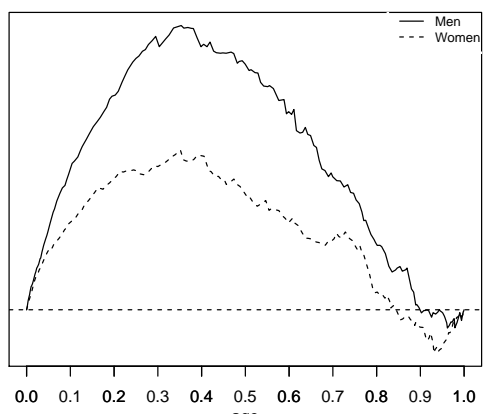

Hourly earnings - GR

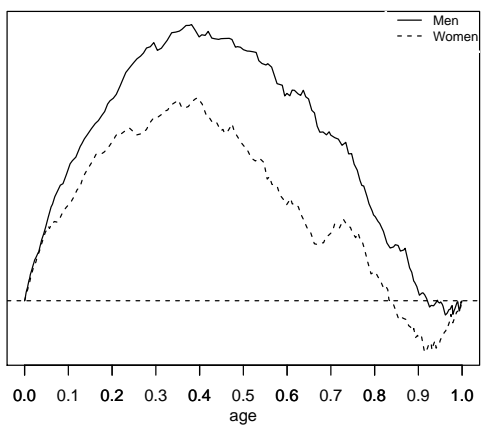

Italy

Employment - IT

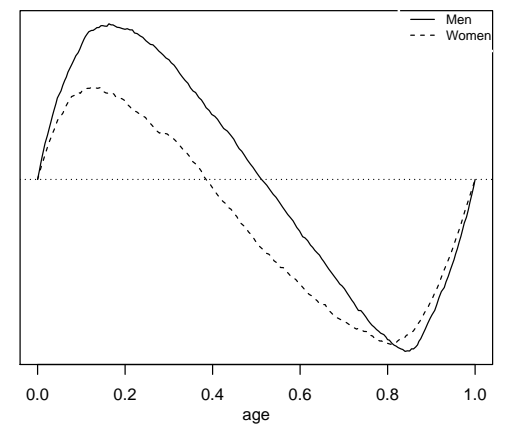

Annual earnings - IT

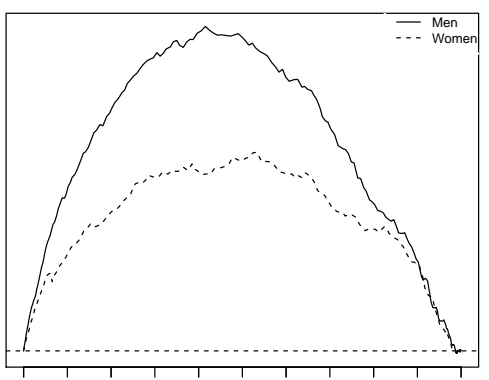

$\begin{array}{lllllllllll}0.0 & 0.1 & 0.2 & 0.3 & 0.4 & 0.5 & 0.6 & 0.7 & 0.8 & 0.9 & 1.0\end{array}$

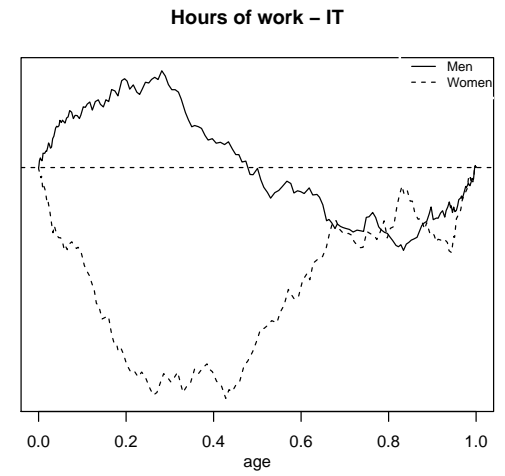

Hourly earnings - IT

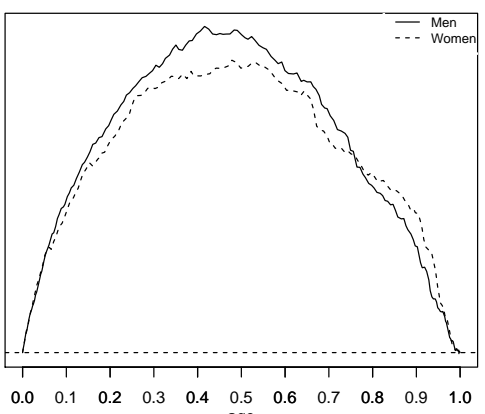




\section{Portugal}
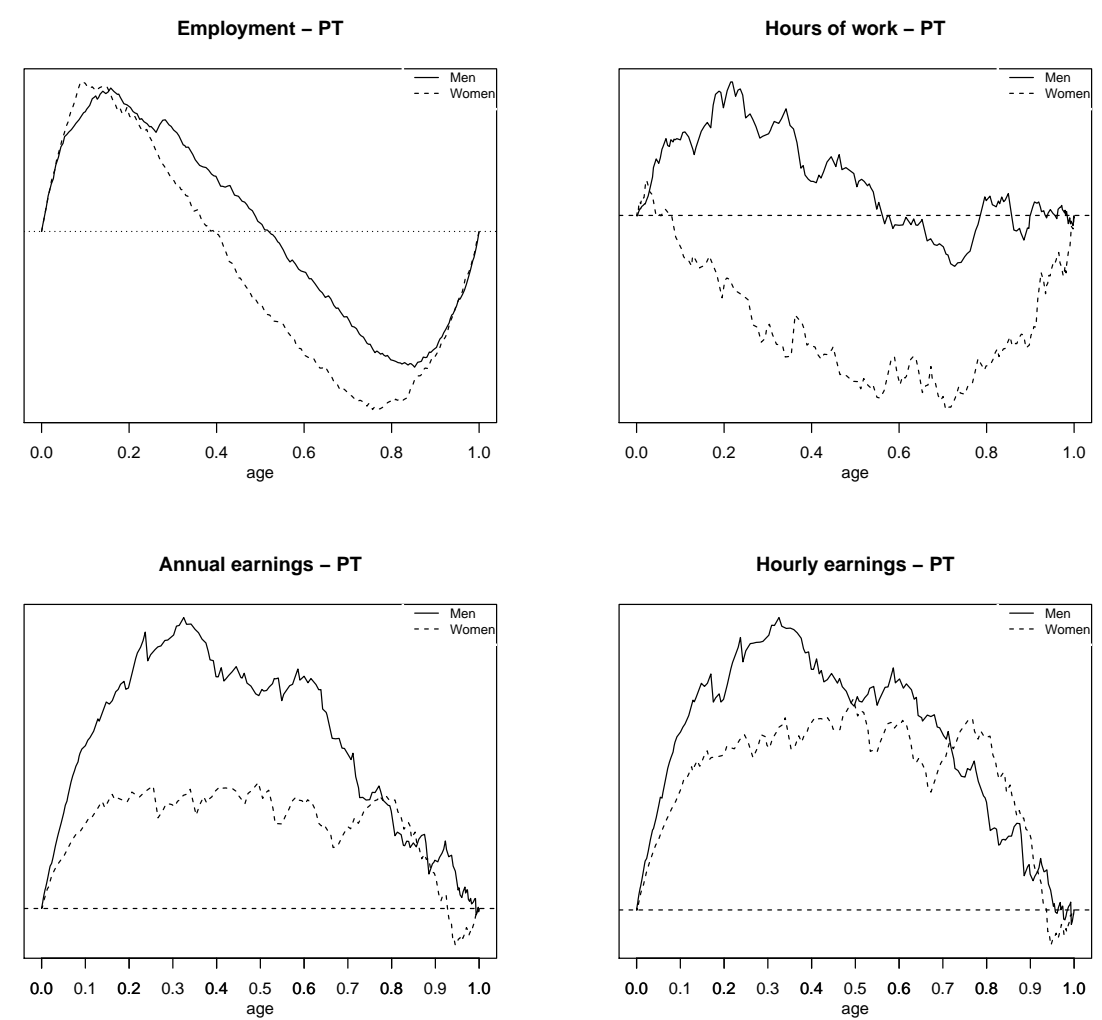

Spain
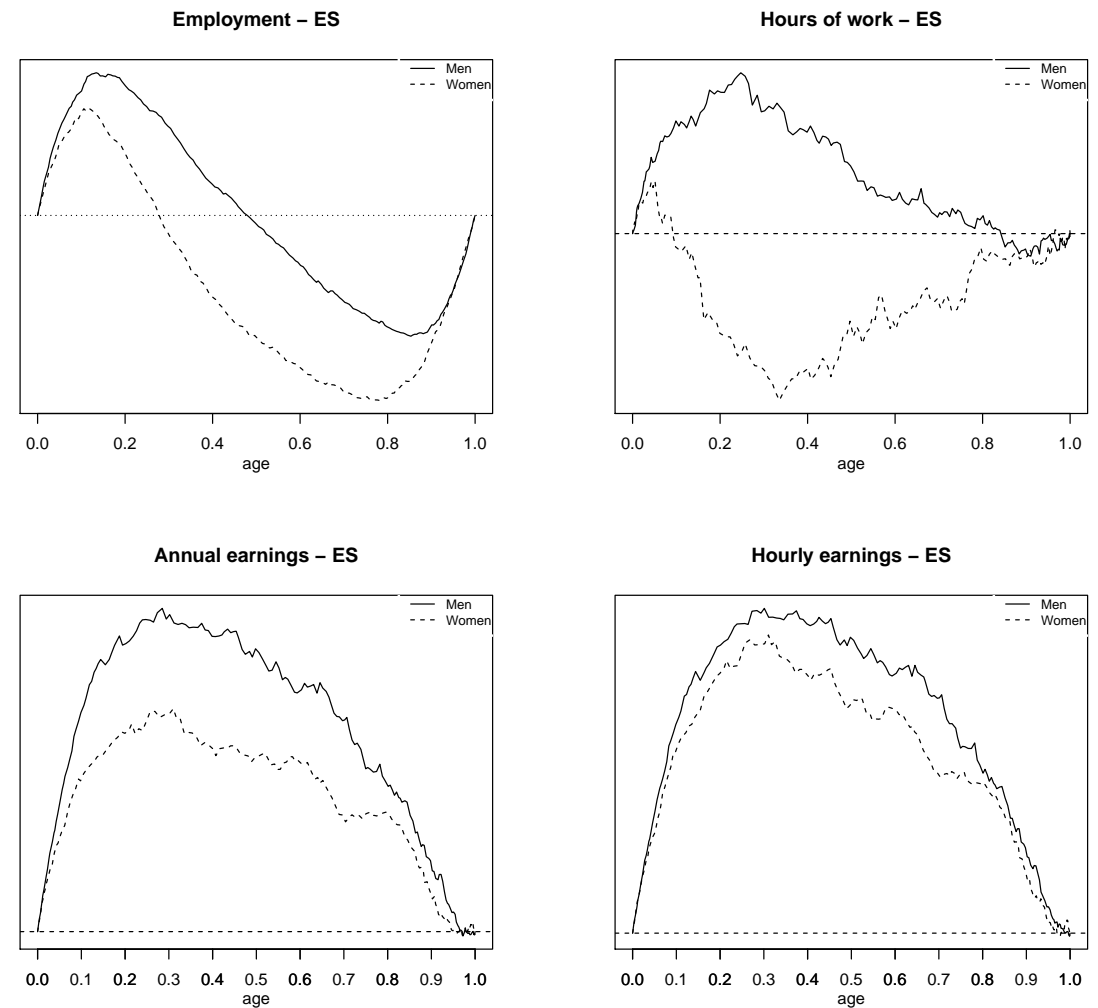
A.3 Third group: Austria, Belgium, Czech Republic, France, Germany, Ireland, Luxembourg, The Netherlands, Slovakia, United Kingdom.

\section{Austria}
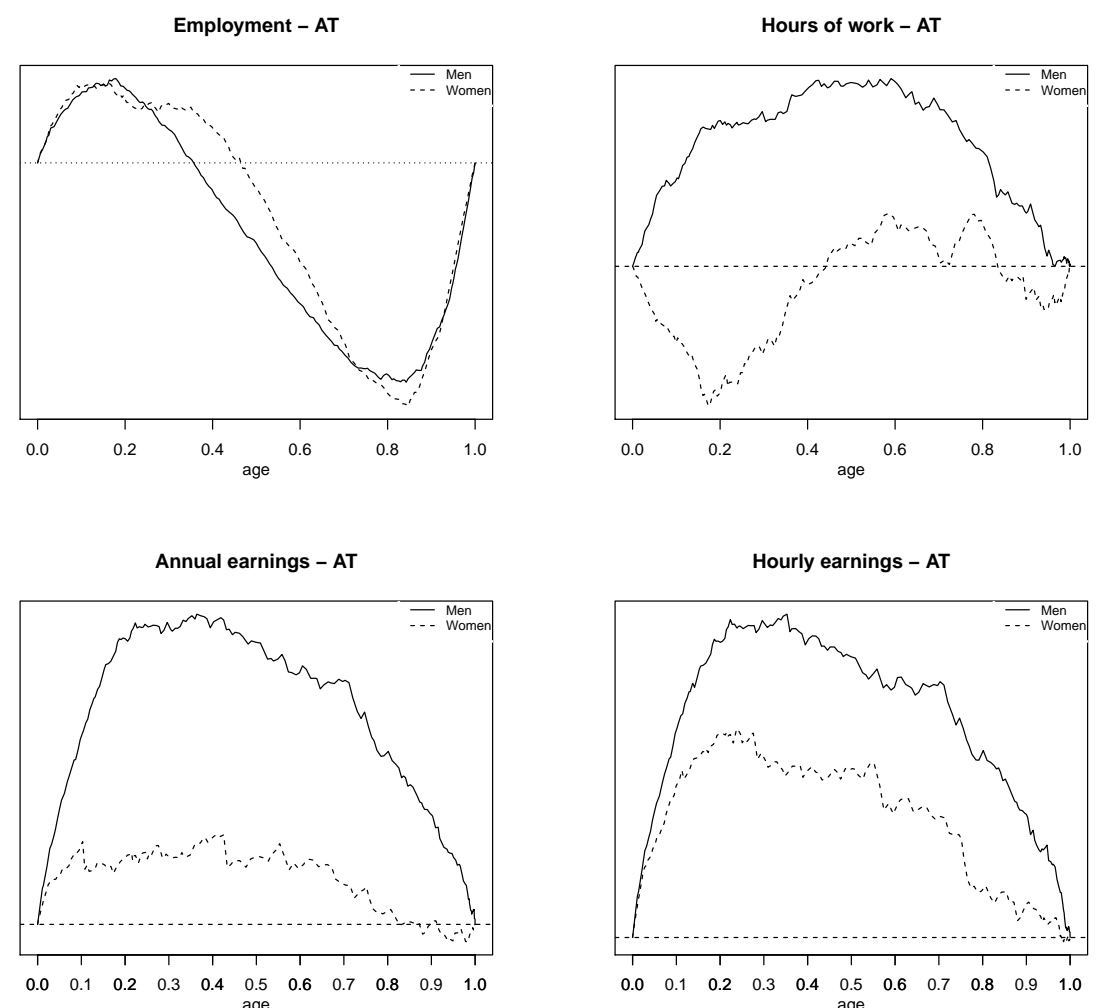


\section{Belgium}

Employment - BE

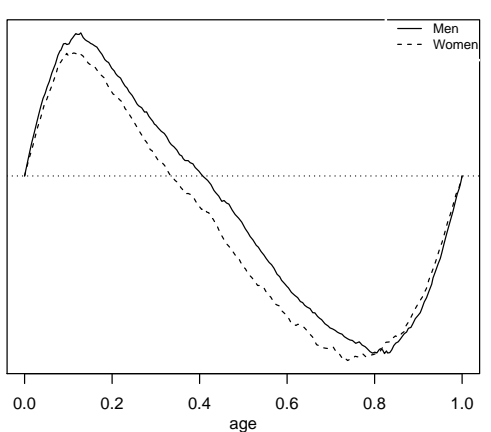

Annual earnings - BE

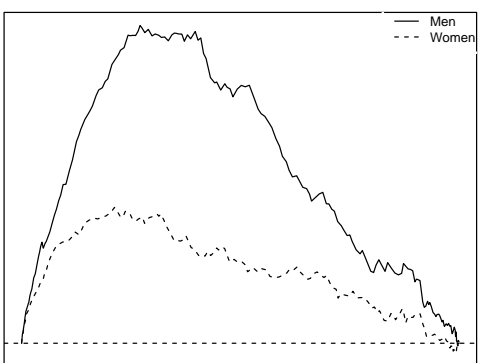

$\begin{array}{lllllllllll}0.0 & 0.1 & 0.2 & 0.3 & 0.4 & 0.5 & 0.6 & 0.7 & 0.8 & 0.9 & 1.0\end{array}$
Hours of work - BE

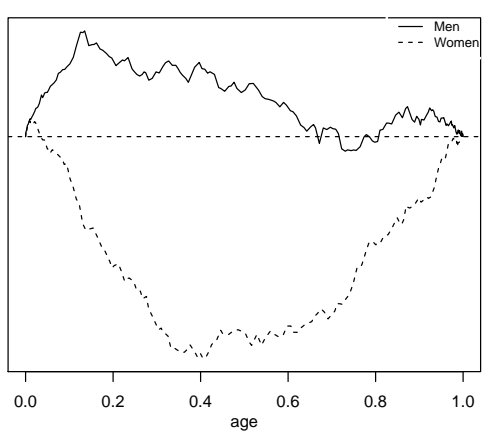

Hourly earnings - BE

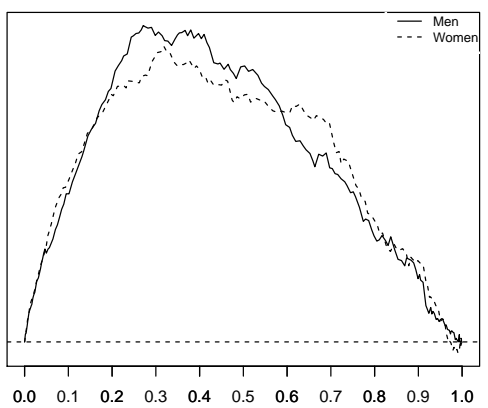

$\begin{array}{lllllllllll}0.0 & 0.1 & 0.2 & 0.3 & 0.4 & 0.5 & 0.6 & 0.7 & 0.8 & 0.9 & 1.0\end{array}$

\section{Czech Republic}
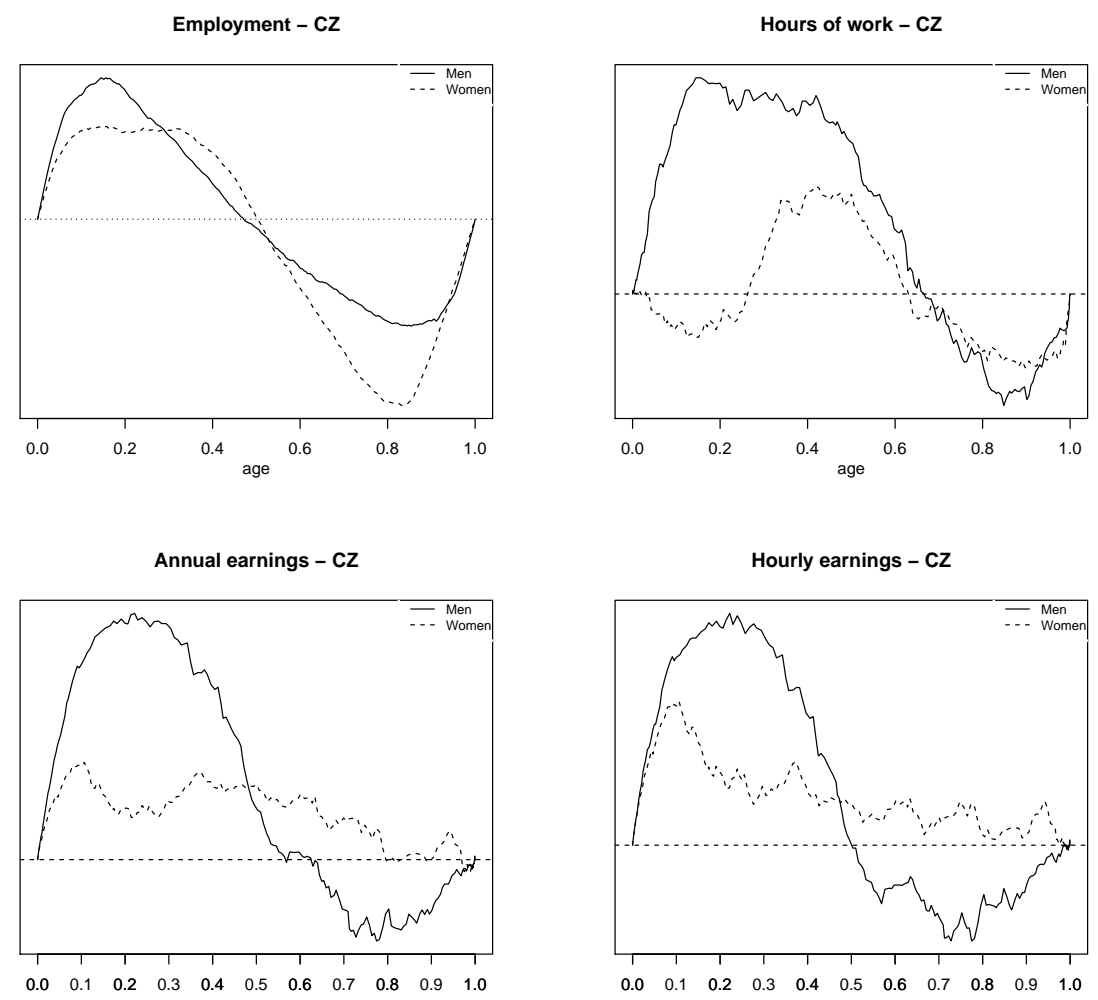

$\begin{array}{lllllllllll}0.0 & 0.1 & 0.2 & 0.3 & 0.4 & 0.5 & 0.6 & 0.7 & 0.8 & 0.9 & 1.0 \\ \text { age } & & & & & & & \end{array}$ 


\section{France}
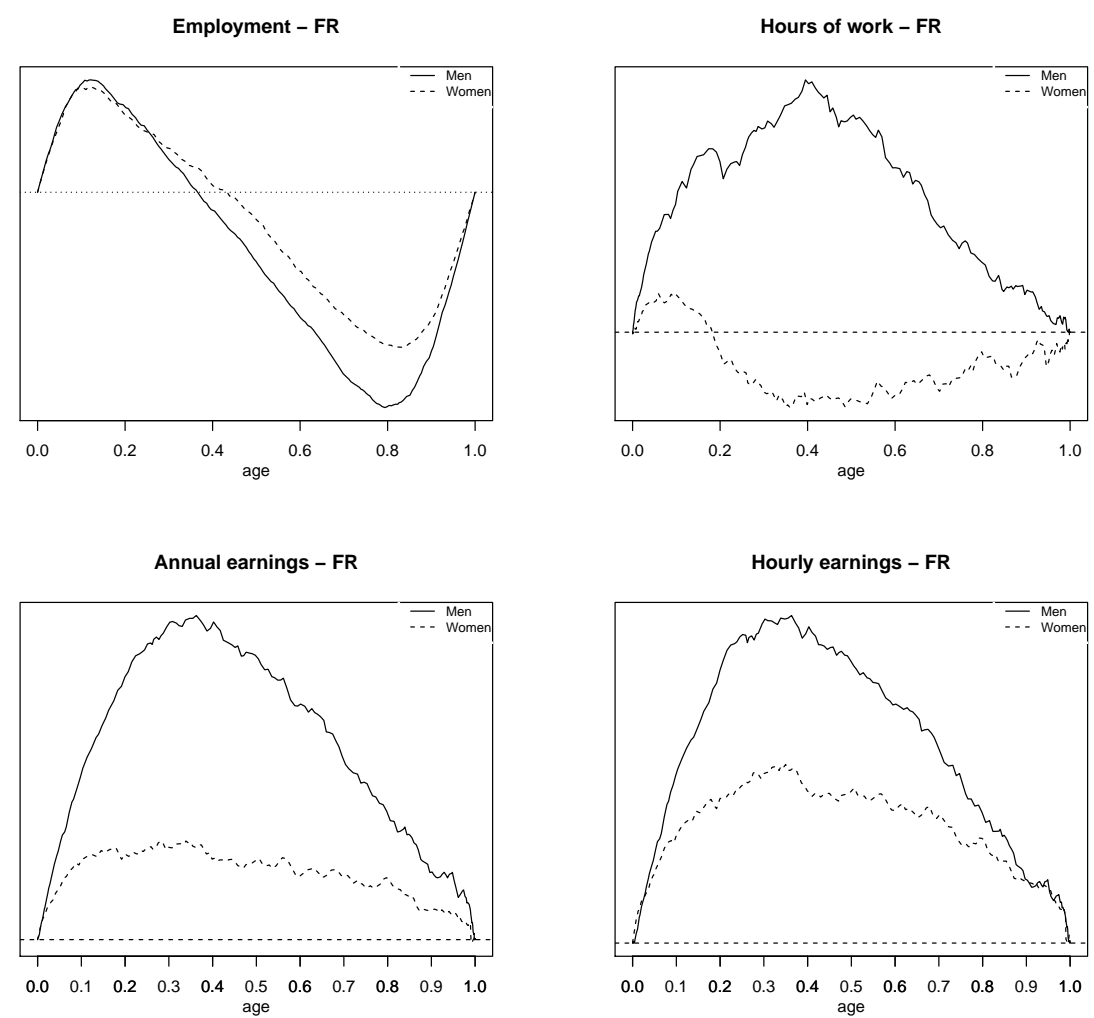

\section{Germany}
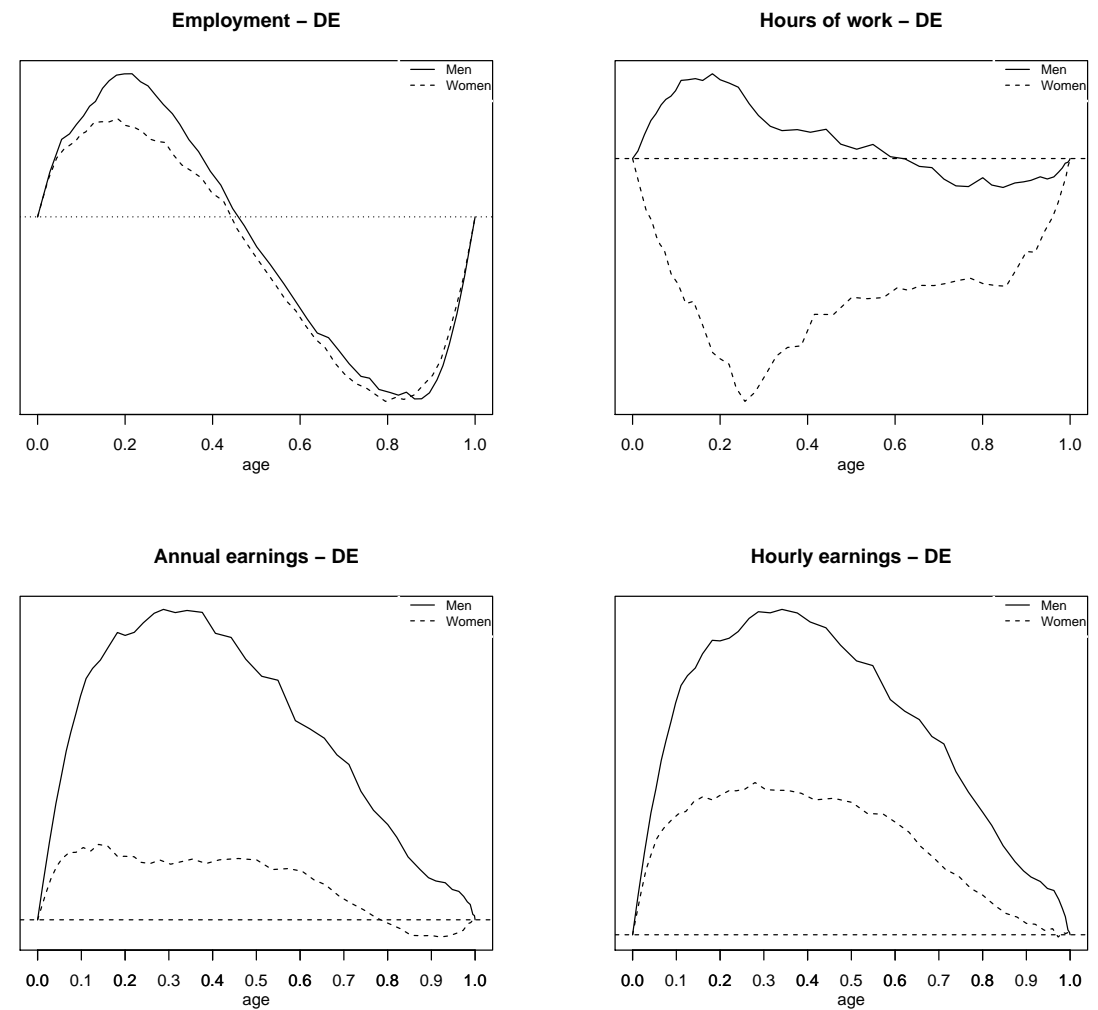


\section{Ireland}
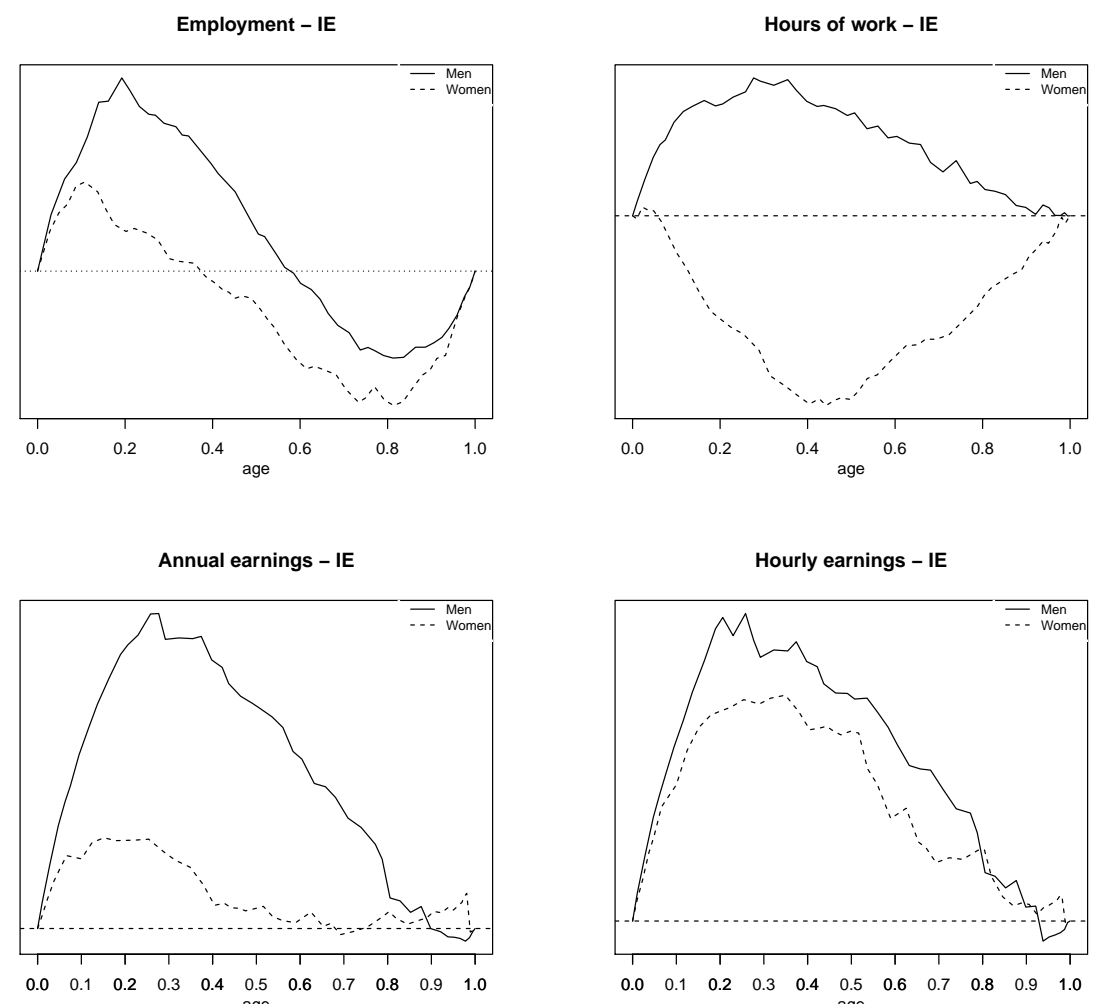

\section{Luxembourg}

Employment - LU

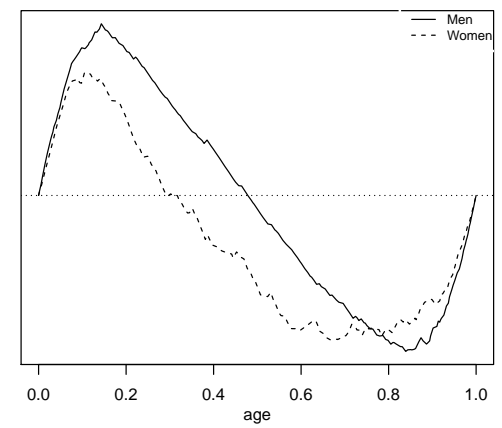

Annual earnings - LU

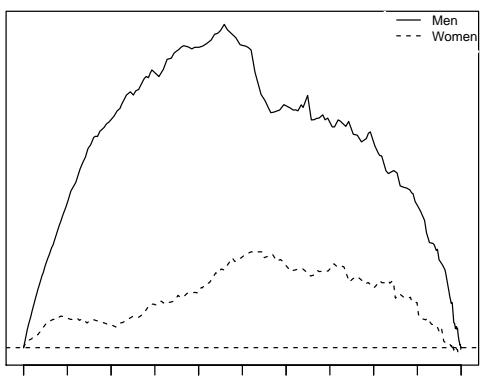

$\begin{array}{lllllllllll}0.0 & 0.1 & 0.2 & 0.3 & 0.4 & 0.5 & 0.6 & 0.7 & 0.8 & 0.9 & 1.0\end{array}$
Hours of work - LU

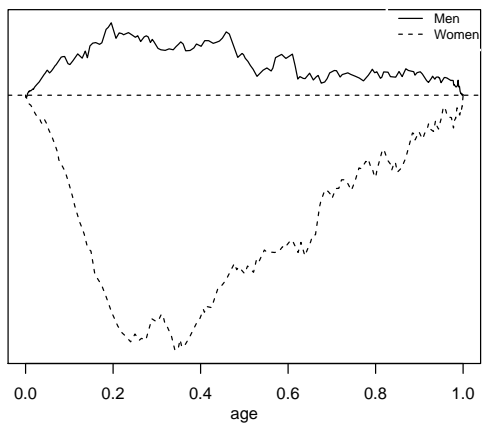

Hourly earnings - LU

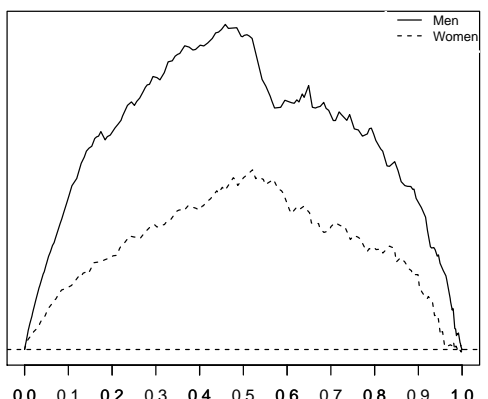

age 


\section{The Netherlands}

Employment - NL

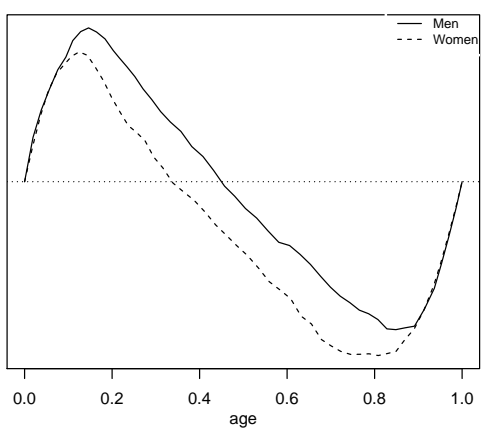

Annual earnings - NL

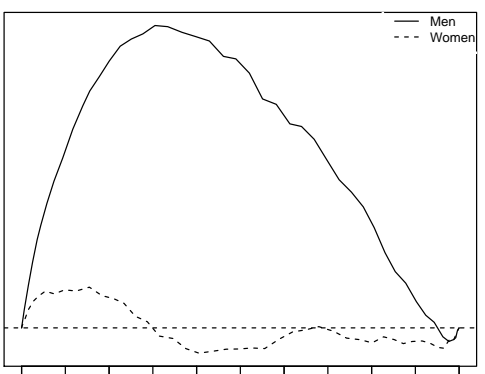

$\begin{array}{lllllllllll}0.0 & 0.1 & 0.2 & 0.3 & 0.4 & \begin{array}{c}0.5 \\ \text { age }\end{array} & 0.6 & 0.7 & 0.8 & 0.9 & 1.0\end{array}$
Hours of work - NL

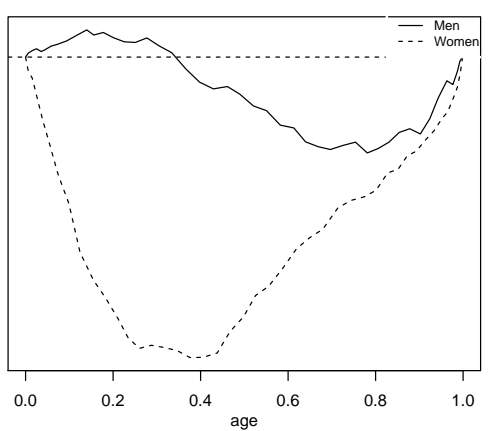

Hourly earnings - NL

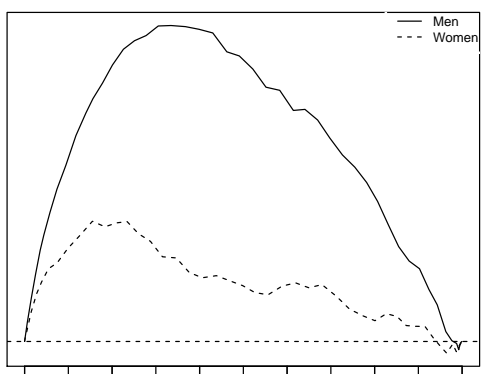

$\begin{array}{lllllllllll}0.0 & 0.1 & 0.2 & 0.3 & 0.4 & 0.5 & 0.6 & 0.7 & 0.8 & 0.9 & 1.0\end{array}$

\section{Slovakia}

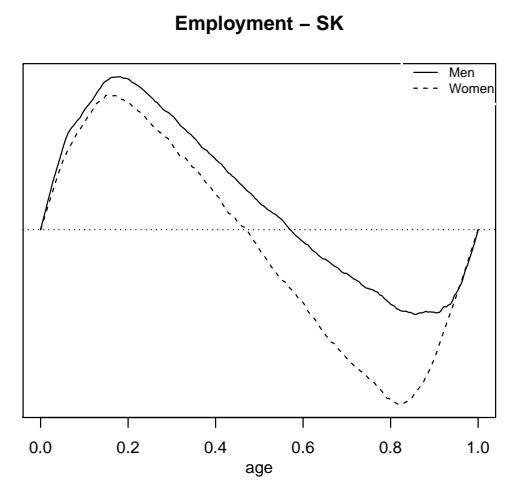

Hours of work - SK

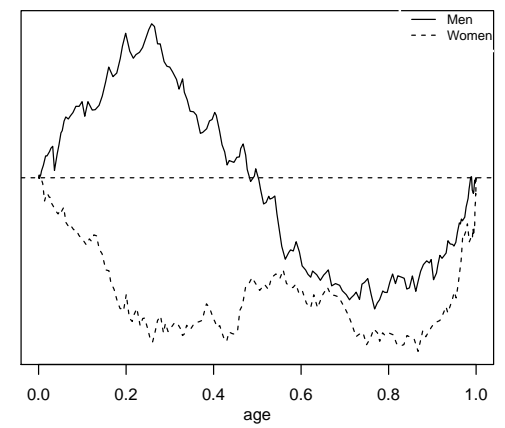

Annual earnings - SK

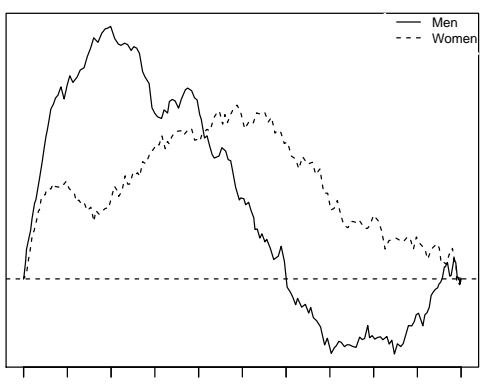

$\begin{array}{lllllllllll}0.0 & 0.1 & 0.2 & 0.3 & 0.4 & 0.5 & 0.6 & 0.7 & 0.8 & 0.9 & 1.0\end{array}$

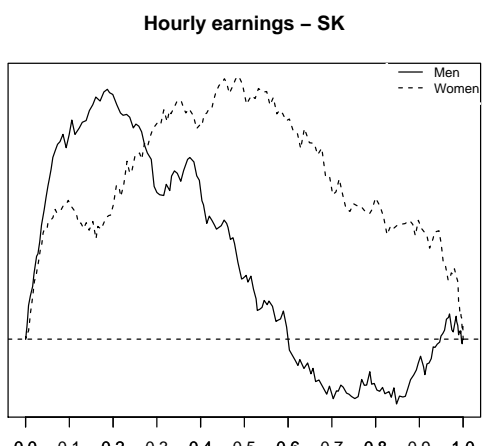

$\begin{array}{lllllllllll}0.0 & 0.1 & 0.2 & 0.3 & 0.4 & 0.5 & 0.6 & 0.7 & 0.8 & 0.9 & 1.0\end{array}$ 
United Kingdom
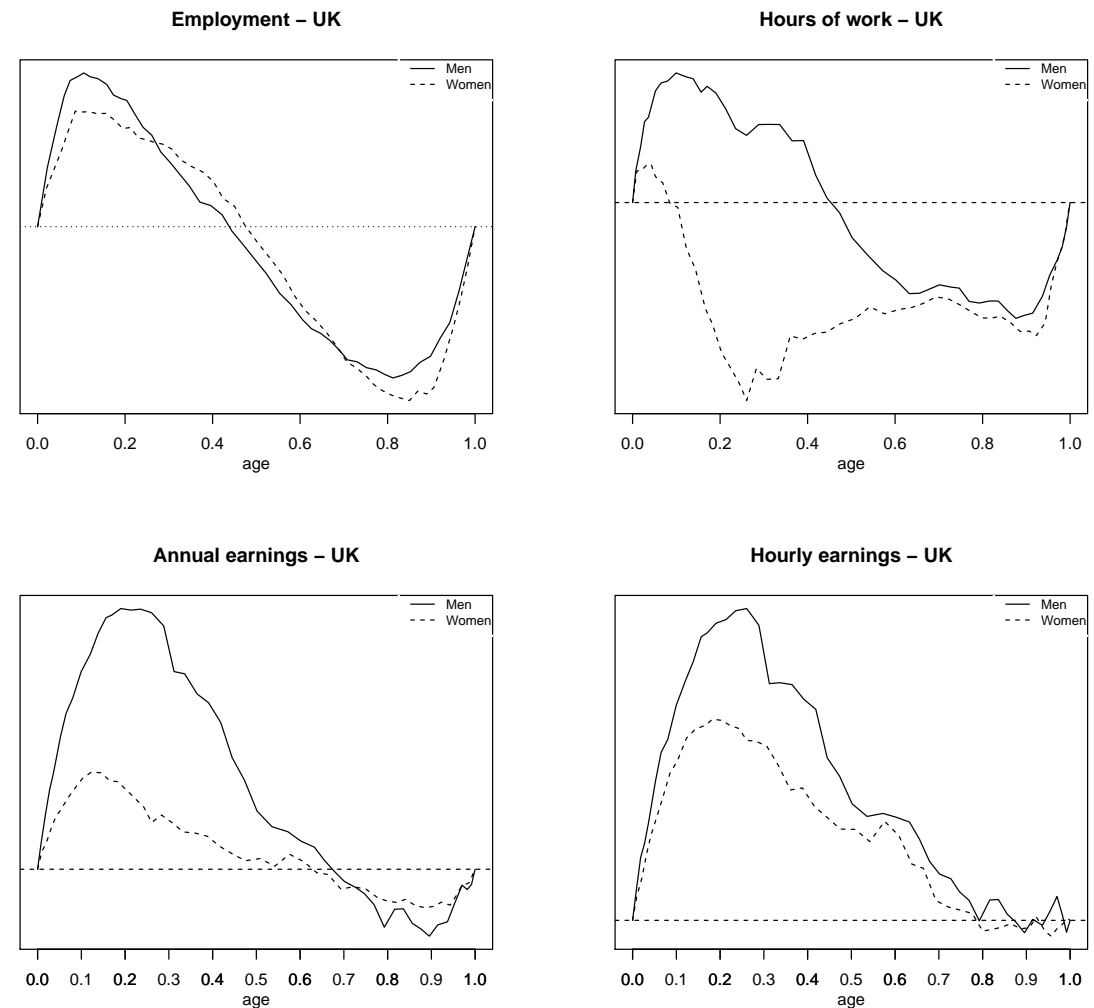

A.4 Fourth group: Estonia, Finland, Latvia, Poland, Romania, Slovenia. 


\section{Estonia}
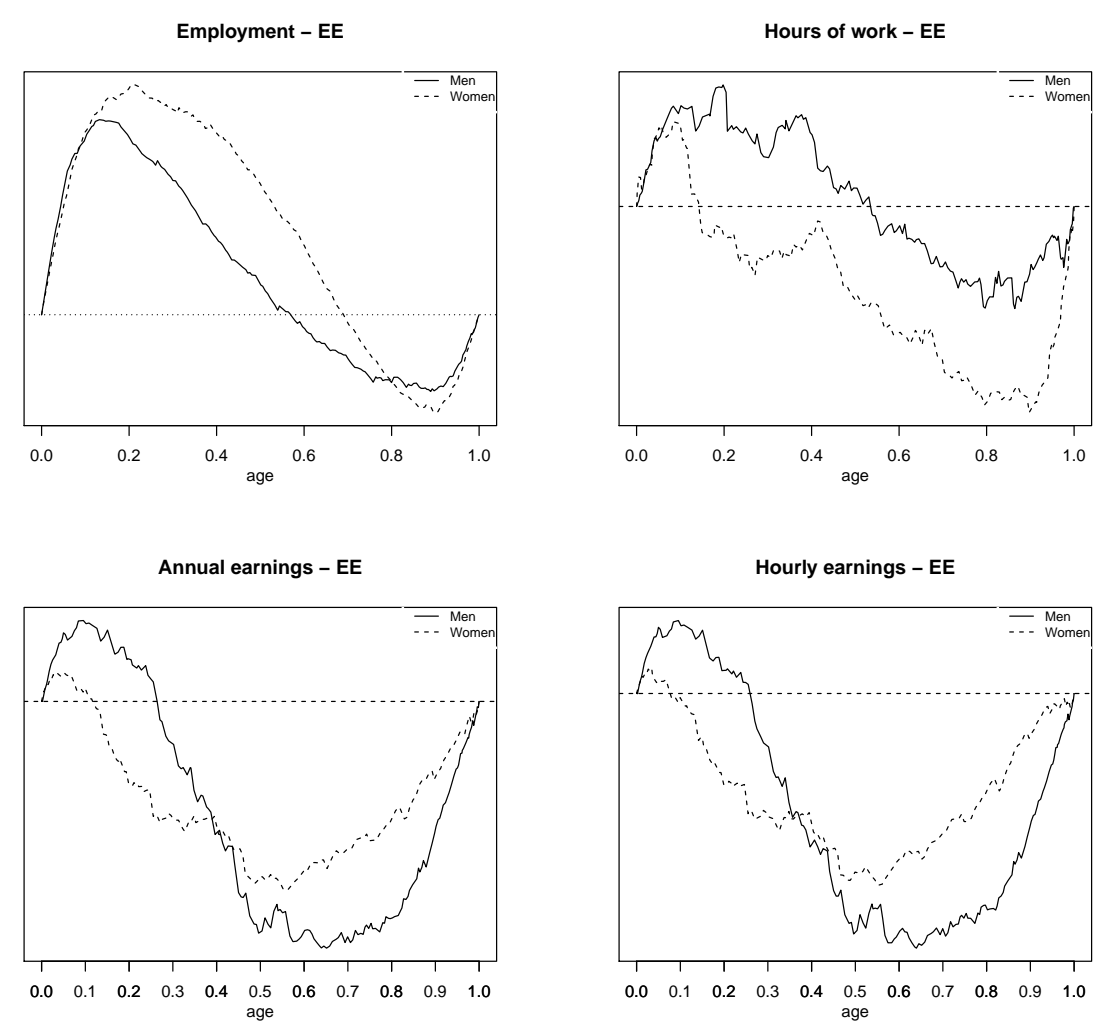

Finland
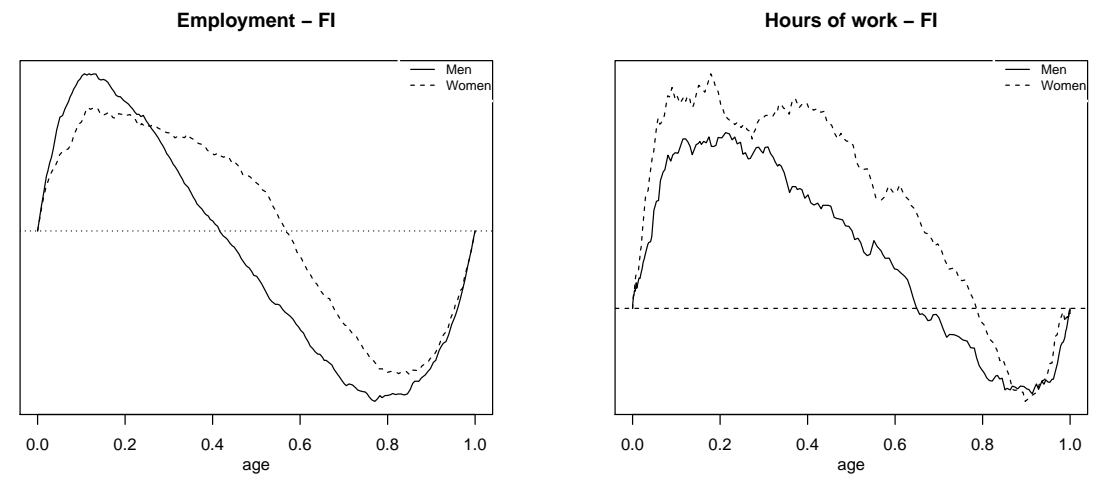

Annual earnings - FI

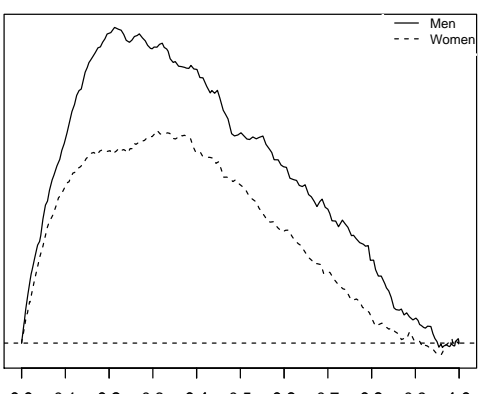

$\begin{array}{lllllllllll}0.0 & 0.1 & 0.2 & 0.3 & 0.4 & 0.5 & 0.6 & 0.7 & 0.8 & 0.9 & 1.0\end{array}$

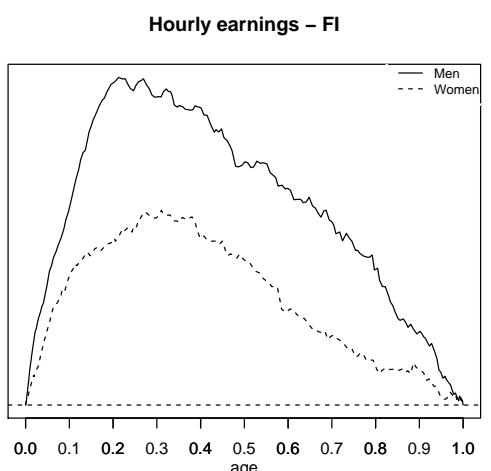




\section{Latvia}
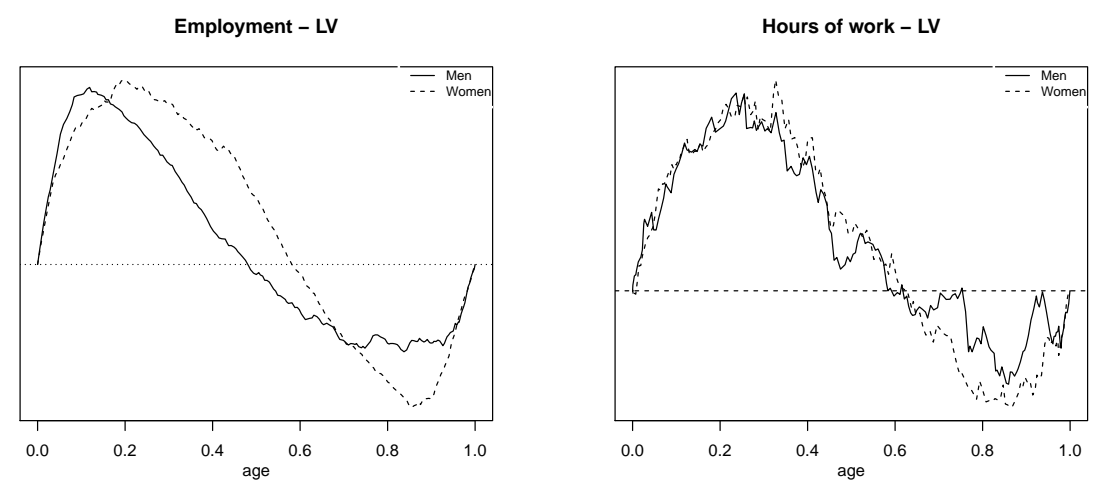

Annual earnings - LV

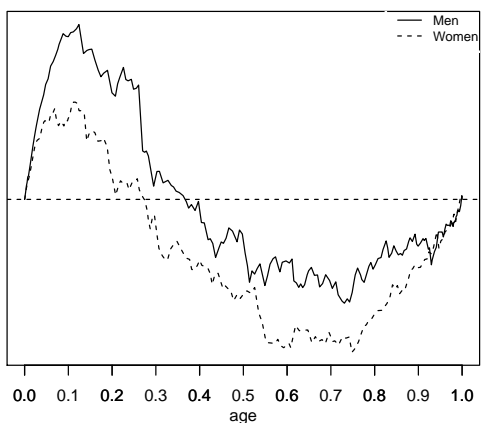

Hourly earnings - LV

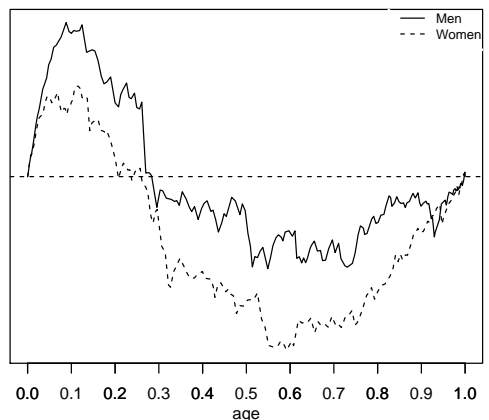

Poland

Employment - PL

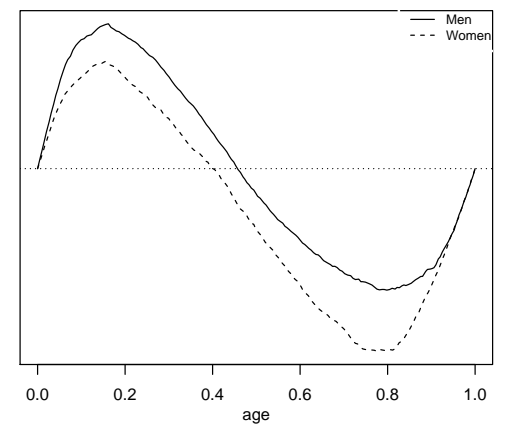

Annual earnings - PL

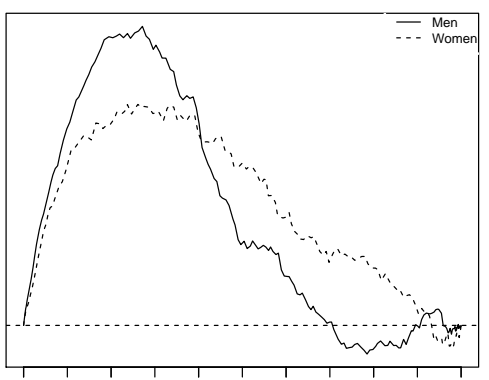

$\begin{array}{lllllllllll}0.0 & 0.1 & 0.2 & 0.3 & 0.4 & 0.5 & 0.6 & 0.7 & 0.8 & 0.9 & 1.0\end{array}$
Hours of work - PL

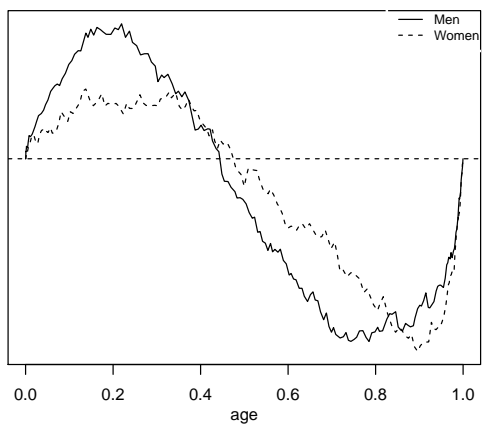

Hourly earnings - PL

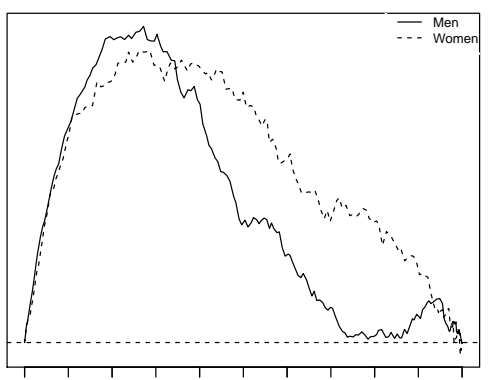

$\begin{array}{lllllllllll}0.0 & 0.1 & 0.2 & 0.3 & 0.4 & 0.5 & 0.6 & 0.7 & 0.8 & 0.9 & 1.0\end{array}$ 


\section{Romania}

Employment - RO

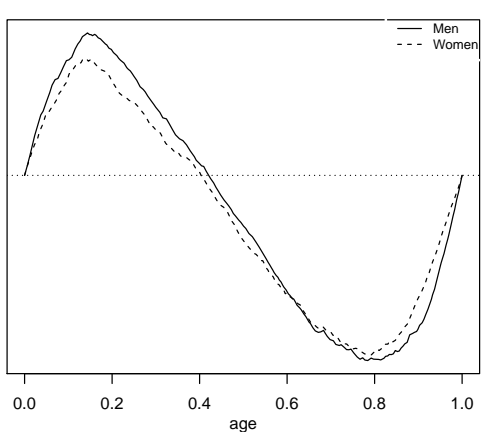

Annual earnings - RO

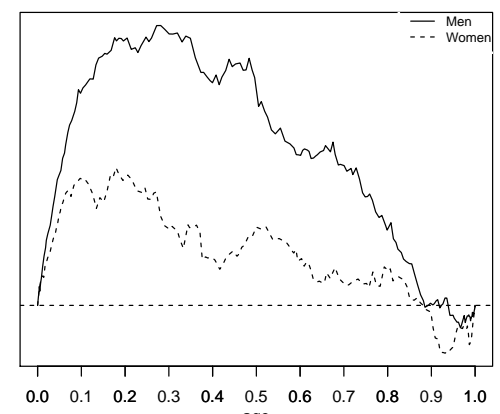

$\begin{array}{lllllllllll}0.0 & 0.1 & 0.2 & 0.3 & 0.4 & \begin{array}{c}0.5 \\ \text { age }\end{array} & 0.6 & 0.7 & 0.8 & 0.9 & 1.0\end{array}$
Hours of work - RO

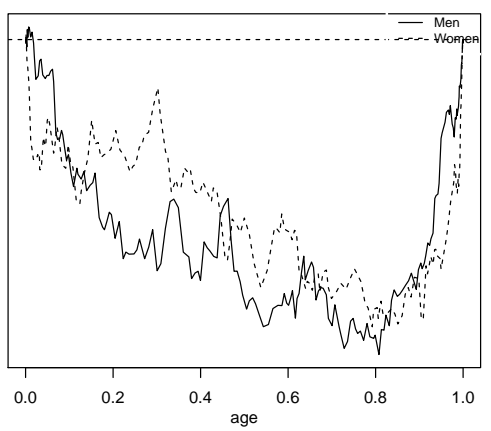

Hourly earnings - RO

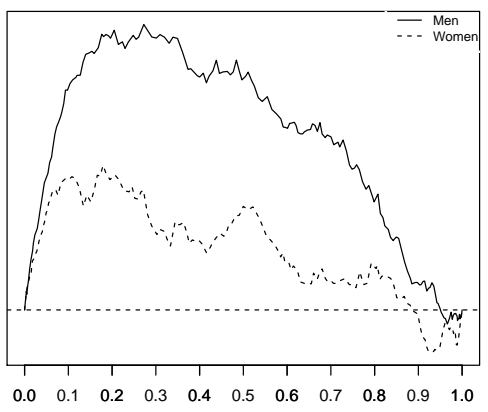

\section{Slovenia}

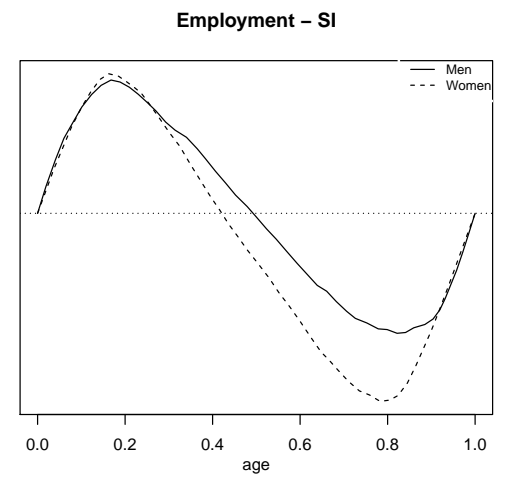

Hours of work - SI

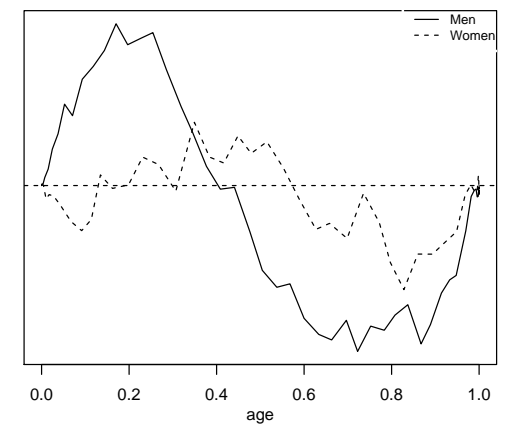

Annual earnings - SI

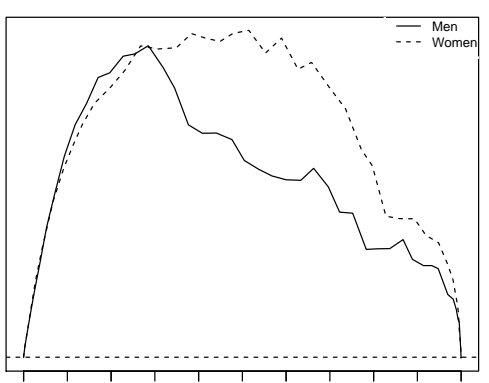

$\begin{array}{lllllllllll}0.0 & 0.1 & 0.2 & 0.3 & 0.4 & 0.5 & 0.6 & 0.7 & 0.8 & 0.9 & 1.0\end{array}$

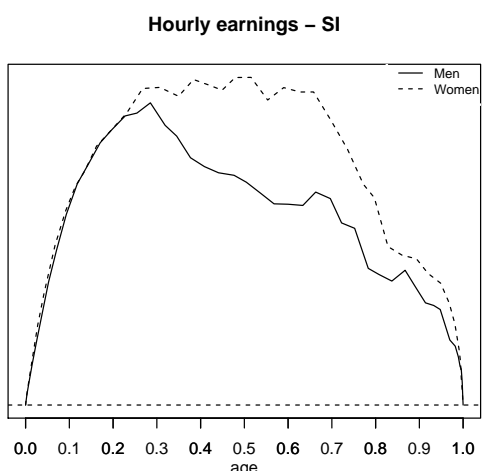




\section{A.5 Fifth group: Bulgaria, Hungary, Lithuania.}

\section{Bulgaria}
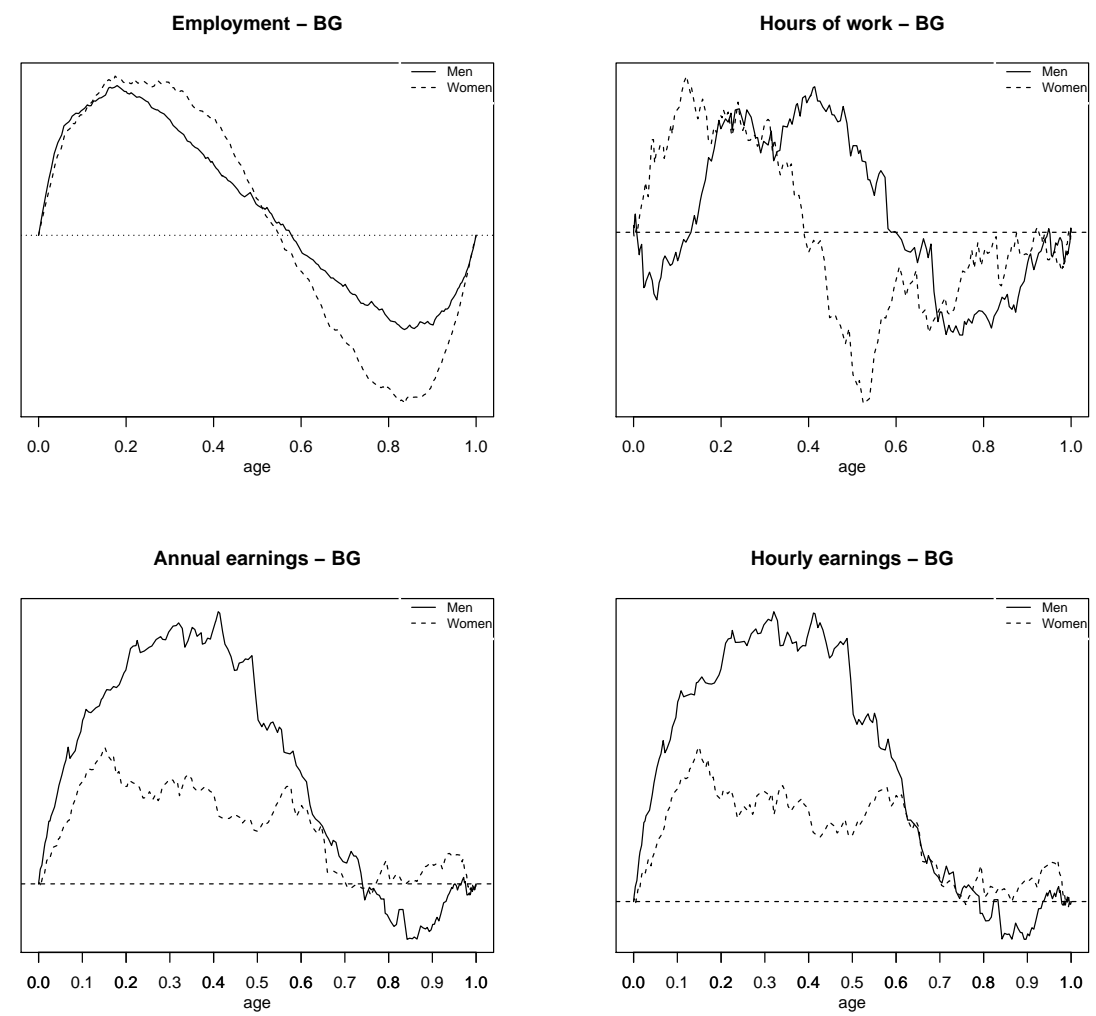


\section{Hungary}
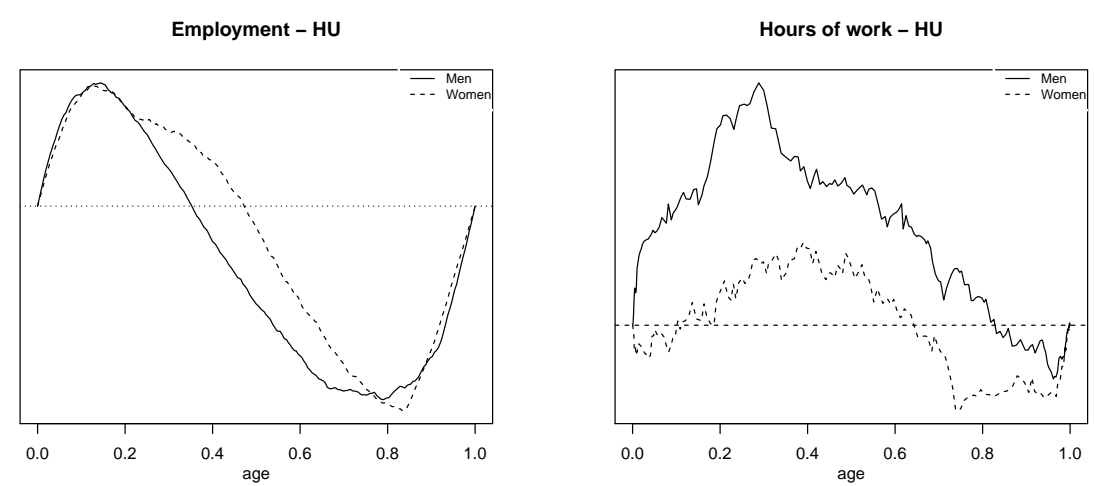

Annual earnings - HU

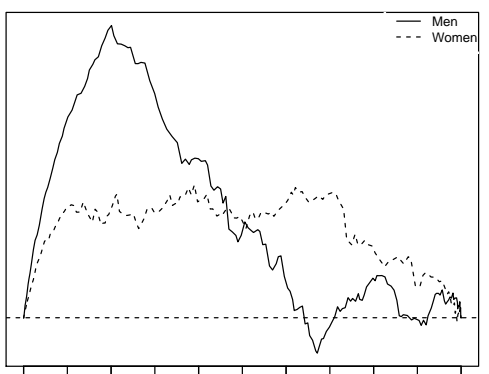

Hourly earnings - HU

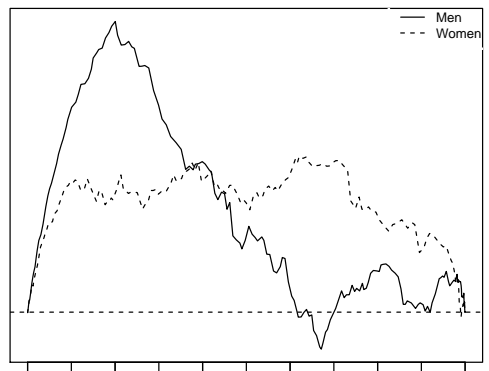

$\begin{array}{lllllllllll}0.0 & 0.1 & 0.2 & 0.3 & 0.4 & \begin{array}{c}0.5 \\ \text { age }\end{array} & 0.6 & 0.7 & 0.8 & 0.9 & 1.0\end{array}$ $\begin{array}{lllllllllll}0.0 & 0.1 & 0.2 & 0.3 & 0.4 & 0.5 & 0.6 & 0.7 & 0.8 & 0.9 & 1.0 \\ \text { age } & & & & & & \end{array}$

\section{Lithuania}

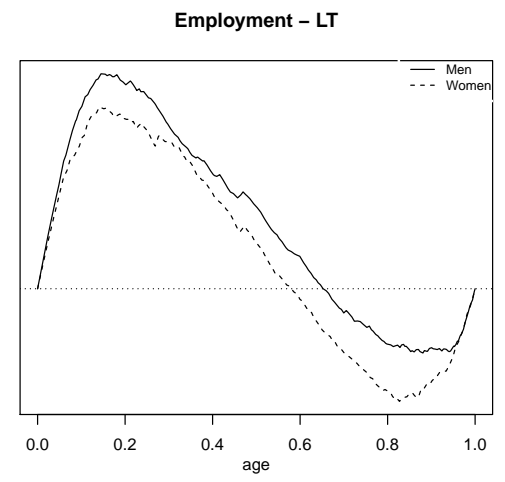

Hours of work - LT

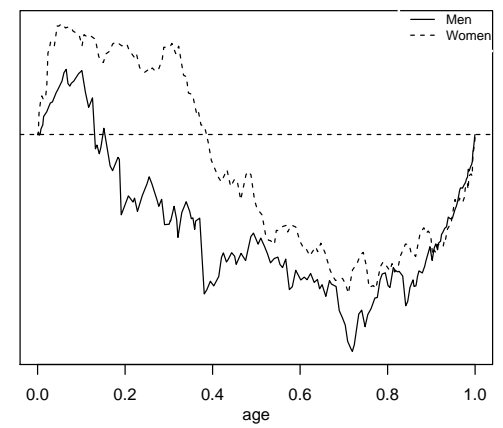

Annual earnings - LT

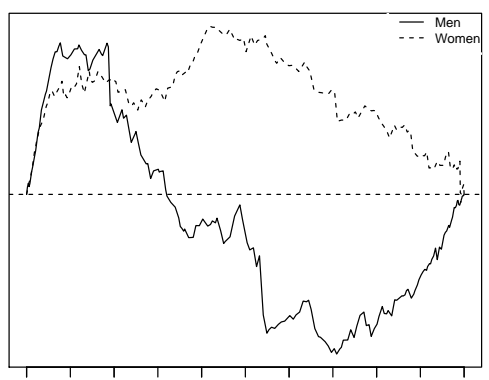

Hourly earnings - LT

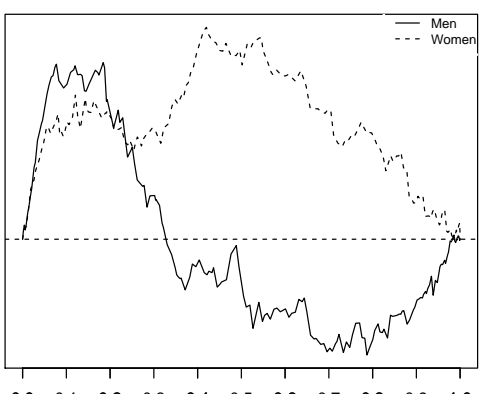

$\begin{array}{lllllllllll}0.0 & 0.1 & 0.2 & 0.3 & 0.4 & 0.5 & 0.6 & 0.7 & 0.8 & 0.9 & 1.0\end{array}$ 


\section{B Decomposition of the Gini regression coefficients in five representative countries}

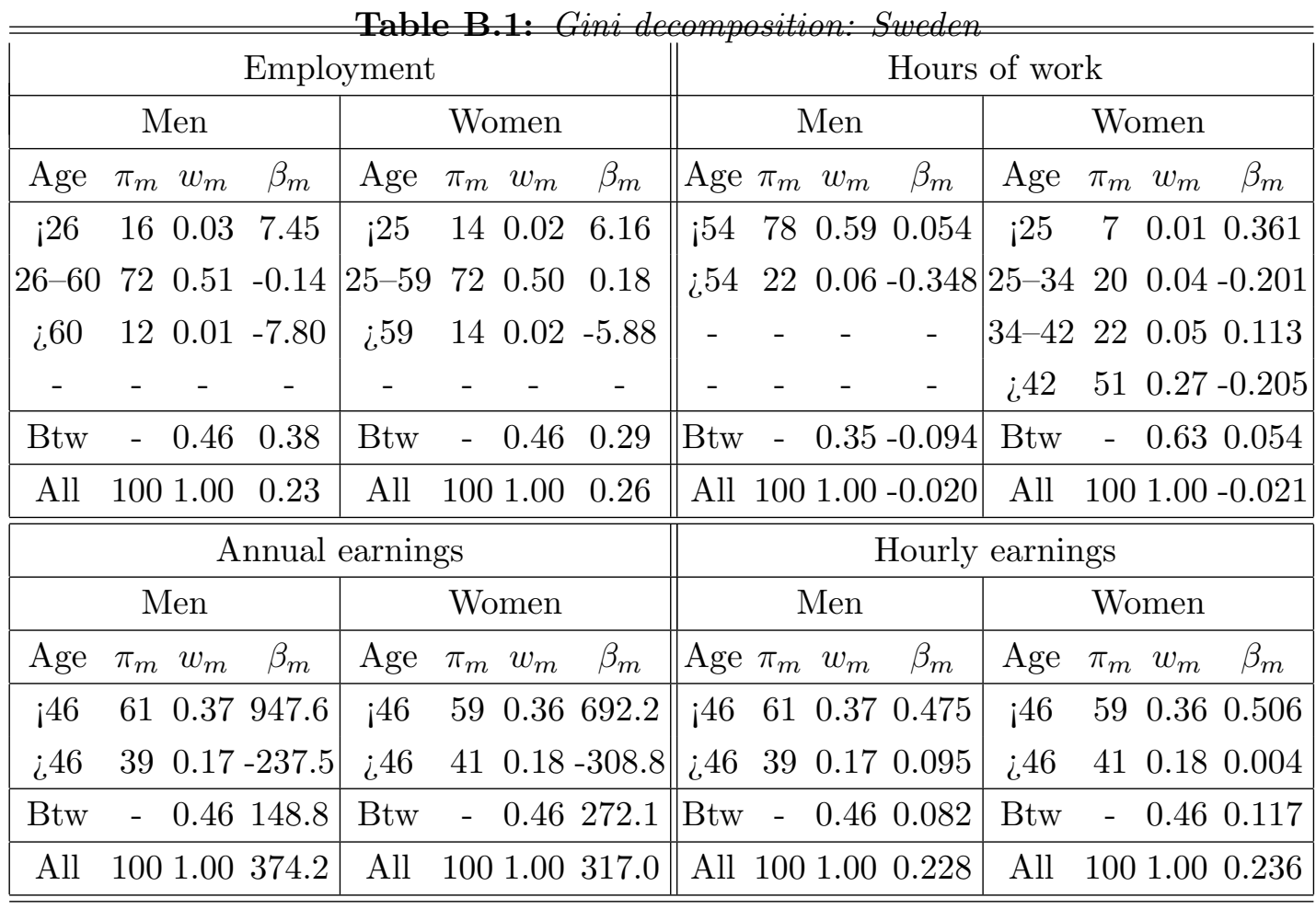

Note: Due to rounding the weighted sum of the components may not add up perfectly to the overall Gini coefficient. 


\begin{tabular}{|c|c|c|c|c|c|c|c|c|c|c|c|c|c|}
\hline \multicolumn{8}{|c|}{ Employment } & \multicolumn{6}{|c|}{ Hours of work } \\
\hline \multicolumn{4}{|c|}{ Men } & \multicolumn{4}{|c|}{ Women } & \multicolumn{3}{|c|}{ Men } & \multicolumn{3}{|c|}{ Women } \\
\hline Age & $\pi_{m}$ & $w_{m}$ & $\beta_{m}$ & Age & $\pi_{m}$ & $w_{m}$ & $\beta_{m}$ & Age & $\pi_{m}$ & $w_{m} \quad \beta_{m}$ & Age & $\pi_{m} w_{m}$ & $\beta_{m}$ \\
\hline ¡29 & 19 & 0.05 & 6.35 & ¡26 & 15 & 0.03 & 6.19 & ¡35 & 28 & $\begin{array}{ll}0.11 & 0.067\end{array}$ & ¡39 & $42 \quad 0.20$ & -0.130 \\
\hline $29-58$ & 67 & 0.42 & 0.00 & $26-56$ & 68 & 0.45 & -0.25 & $35-53$ & 55 & $0.27-0.029$ & $39-51$ & 390.14 & 0.070 \\
\hline ¿.58 & 14 & 0.02 & -5.17 & ¿56 & 17 & 0.03 & -4.35 & ¿53 & 17 & $0.05-0.048$ & ¿51 & 190.06 & -0.1 \\
\hline Btw & - & 0.51 & -0.35 & Btw & - & 0.4 & -0.54 & Btw & - & $0.57-0.010$ & Btw & - 0.60 & -0 . \\
\hline All & 100 & 1.00 & 0.02 & All & 100 & 1.0 & -0.32 & All & 100 & $1.00-0.002$ & All & 1001.0 & -0.0 \\
\hline \multicolumn{8}{|c|}{ Annual earnings* } & \multicolumn{6}{|c|}{ Hourly earnings* } \\
\hline \multicolumn{4}{|c|}{ Men } & \multicolumn{4}{|c|}{ Women } & \multicolumn{3}{|c|}{ Men } & \multicolumn{3}{|c|}{ Women } \\
\hline Age & $\pi$ & $w$ & $\beta$ & Age & $\pi$ & $w$ & $\beta$ & Age & $\pi$ & $w$ & Age & $\pi \quad w$ & $\beta$ \\
\hline All & & & 528.9 & All & & & 337.6 & All & & 0.248 & All & & 0.235 \\
\hline
\end{tabular}

Note: Due to rounding the weighted sum of the components may not add up perfectly to the overall Gini coefficient.

* Given linearity, no decomposition is needed.

Table B.3: Gini decomposition: Germany

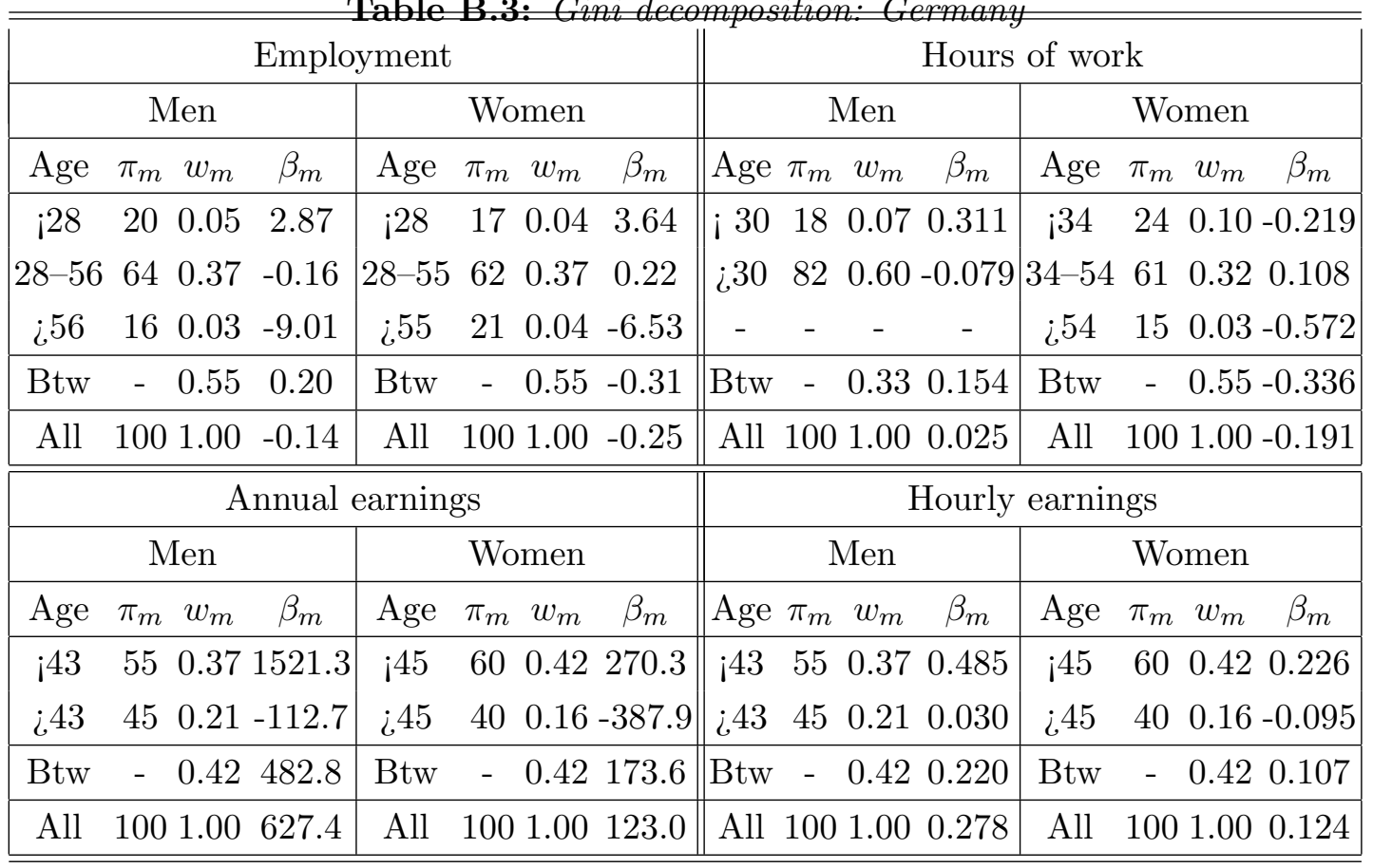

Note: Due to rounding the weighted sum of the components may not add up perfectly to the overall Gini coefficient. 


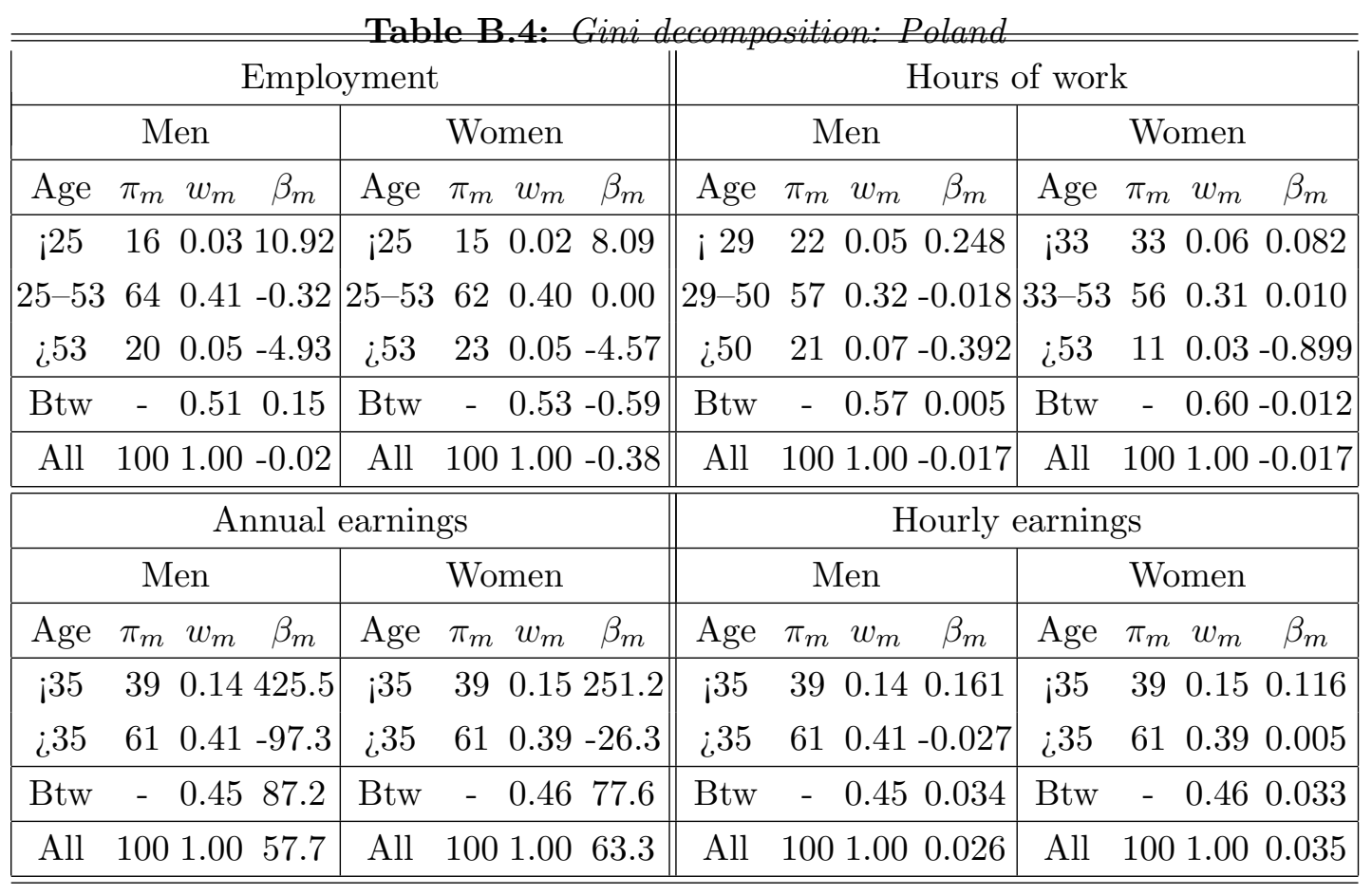

Note: Due to rounding the weighted sum of the components may not add up perfectly to the overall Gini coefficient.

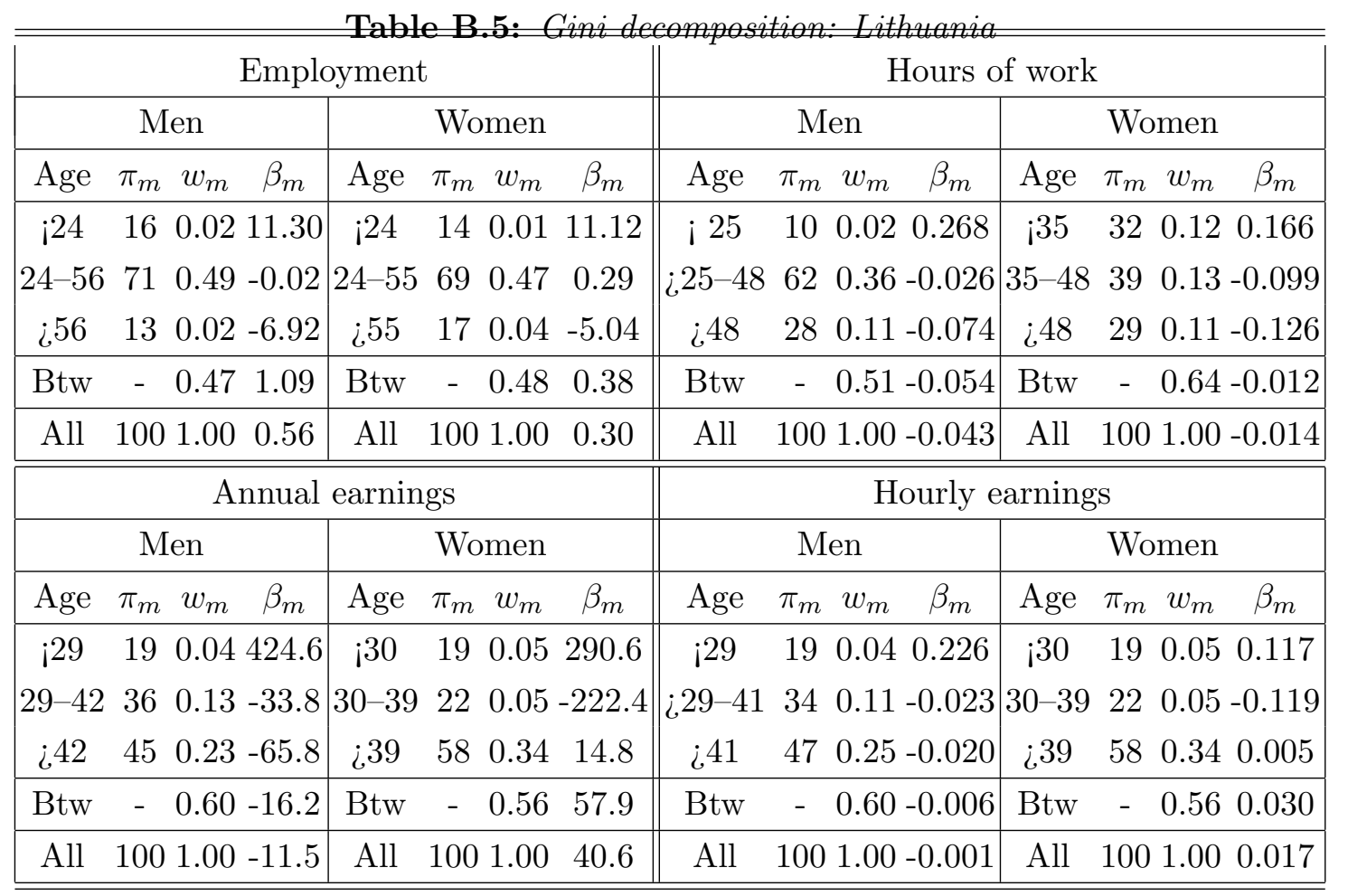

Note: Due to rounding the weighted sum of the components may not add up perfectly to the overall Gini coefficient. 